\title{
Computational modeling predicts acidic microdomains in the glutamatergic synaptic cleft
}

\author{
Touhid Feghhi, ${ }^{1}$ Roberto X. Hernandez, ${ }^{2,3,4}$ Michal Stawarski, ${ }^{5}$ Connon I. Thomas, ${ }^{6}$ Naomi \\ Kamasawa, ${ }^{6}$ A.W.C. Lau, ${ }^{1}$ and Gregory T. Macleod,${ }^{4,5,7^{*}}$
}

1. Department of Physics, College of Science, Florida Atlantic University, Boca Raton, FL, 33431, USA

2. Integrative Biology \& Neuroscience Graduate Program, Florida Atlantic University, Boca Raton, FL 33431, USA

3. International Max Planck Research School for Brain and Behavior, Jupiter, FL 33458, USA.

4. Jupiter Life Sciences Initiative, Florida Atlantic University, Jupiter, FL 33458, USA

5. Wilkes Honors College, Florida Atlantic University, Jupiter, FL, 33458, USA

6. Electron Microscopy Core Facility, Max Planck Florida Institute, Jupiter, Florida 33458,

7. Brain Institute, Florida Atlantic University, Jupiter, FL 33458, USA

*Correspondence: macleodg@fau.edu

Abbreviated Title: Acidic microdomains in the synaptic cleft

Keywords: synaptic cleft, pH, glutamatergic, synaptic plasticity, ASICs, reaction-diffusion scheme

Number of Text Pages: 38

Number of Figures: 6 main figs, 4 supplemental figs, 5 tables

Number of Words: Summary 229, Significance 120, Introduction 483, Results 2032, Discussion 1207

Conflict of Interest Statement: The authors declare no competing financial interests.

Acknowledgements: This work was supported by NIH NINDS award NS103906 to GTM. Michal Stawarski's current affiliation is with the Department of Biomedicine, University of Basel, Basel, 4056, Switzerland. We are grateful for discussions with Drs. Walter Boron, Robert Renden and Eugene Smith. 


\section{ABSTRACT:}

At chemical synapses, synaptic vesicles release their acidic contents into the cleft leading to the expectation that the cleft should acidify. However, fluorescent $\mathrm{pH}$ probes targeted to the cleft of conventional glutamatergic synapses in both fruit flies and mice reveal cleft alkalinization, rather than acidification. Here, using a reaction-diffusion scheme, we modeled $\mathrm{pH}$ dynamics at the Drosophila neuromuscular junction (NMJ) as glutamate, adenosine triphosphate (ATP) and protons $\left(\mathrm{H}^{+}\right)$are released into the cleft. The model incorporates bicarbonate and phosphate buffering systems as well as plasma membrane calcium-ATPase (PMCA) activity and predicts substantial cleft acidification but only for fractions of a millisecond following neurotransmitter release. Thereafter, the cleft rapidly alkalinizes and remains alkaline for over 100 milliseconds, as the PMCA removes $\mathrm{H}^{+}$from the cleft in exchange for calcium ions $\left(\mathrm{Ca}^{2+}\right)$ from adjacent preand post-synaptic compartments; thus recapitulating the empirical data. The extent of synaptic vesicle loading and time course of exocytosis has little influence on the magnitude of acidification. Phosphate, but not bicarbonate buffering is effective at ameliorating the magnitude and time course of the acid spike, while both buffering systems are effective at ameliorating cleft alkalinization. The small volume of the cleft levies a powerful influence on the magnitude of alkalinization and its time course. Structural features that open the cleft to adjacent spaces appear to be essential for alleviating the extent of $\mathrm{pH}$ disturbances accompanying neurotransmission.

\section{SIGNIFICANCE STATEMENT:}

Acid-base imbalances have surprisingly potent neurological effects highlighting the acute $\mathrm{pH}$ sensitivity of many neural mechanisms. Acid-Sensing lon-Channels (ASICs), which open in response to acid shifts in extracellular $\mathrm{pH}$, are an example of such a mechanism. However, while ASICs open during neurotransmission at conventional glutamatergic synapses, $\mathrm{pH}$ sensitive electrodes and fluorophores show no signs of acidification at these synapses, only alkalinization. To resolve this paradox, we built a computational model which allows a glimpse beyond the experimental limitations of $\mathrm{pH}$-sensitive electrodes and fluorophores. Our model reveals a highly dynamic $\mathrm{pH}$ landscape within the synaptic cleft, harboring deep but exceedingly rapid acid transients that give way to a prolonged period of alkalinization, thus reconciling ASIC activation with direct measurements of extracellular $\mathrm{pH}$. 


\section{INTRODUCTION:}

Any doubt that our nervous system is $\mathrm{pH}$ sensitive is put to rest by the neurological consequences of even the smallest systemic acid/base disturbance [1-5]. The degree to which nerve activity itself can drive $\mathrm{pH}$ change is poorly understood yet any such change would likely impact the efficacy of neurotransmission as voltage-gated calcium channels (VGCCs), glutamate receptors (GluRs), gamma-aminobutyric acid type-A receptors $\left(G A B A_{A} R\right)$ and acidsensing ion channels (ASICs) are exposed at the cleft and are $\mathrm{pH}$-sensitive at their extracellular aspect $[1-3,6]$.

The preponderance of electrophysiological data indicate acidification at vertebrate sensory ribbon synapses during neurotransmission [7-11]. Fluorescent $\mathrm{pH}$ reporters targeted to the cleft at these synapses also reveal acidification $[12,13]$. However, conventional neuronal synapses appear to be different, as fluorescent $\mathrm{pH}$ reporters targeted to such synapses in mice and fruit flies reveal cleft alkalinization without any signs of acidification [14]. Furthermore, alkalinization has also been observed adjacent to glutamatergic synapses in the mammalian hippocampus and cerebellar cortex [15-22]. Yet, it is clear that ASICs are activated at conventional glutamatergic synapses within the amygdala, nucleus accumbens, calyx of Held and cingulate cortex [23-26]. Clearly, these reports of ASIC activation are difficult to reconcile with $\mathrm{pH}$ recordings made beside these synapses and within their clefts.

Here we adopted a computational approach to model competing influences on $\mathrm{pH}$ within the cleft at the Drosophila NMJ. The chemical synapse, the fundamental unit of intercellular communication and neural computation, represents a challenge for any $\mathrm{pH}$ buffering system. It is characterized by a site of close apposition between pre- and post-synaptic neurons; the synaptic cleft. Close apposition is necessary to deliver a package of neurotransmitters at high concentration onto corresponding receptors on the surface of the post-synaptic neuron. However, this confined space is expected to manifest substantial acidification caused by the release of the conjugate acid of neurotransmitters within synaptic vesicles (SVs), and the limited $\mathrm{pH}$ buffering entities present in small interstitial volumes. In opposition to this acidifying influence is the PMCA, a Ca ${ }^{2+} / 2 \mathrm{H}^{+}$exchanger, which exerts an alkalinizing influence on interstitial spaces [27]. $\mathrm{Ca}^{2+}$ enters the presynaptic compartment through VGCCs and $\mathrm{Ca}^{2+}$ enters the postsynaptic compartment through neurotransmitter-gated channels, while the PMCA removes $\mathrm{Ca}^{2+}$ from both compartments in exchange for $\mathrm{H}^{+}$from interstitial spaces.

Using a reaction-diffusion scheme implemented in MATLAB, we modeled the effects on cleft $\mathrm{pH}$ of neurotransmitters and their conjugate acids as they are released from SVs, interact with buffers, and diffuse away from the release site. Furthermore, we incorporated into this 
model the effect of PMCA and the effect of opening the synaptic cleft to the voids within the adjacent postsynaptic folds. We found that this conventional glutamatergic synapse will, as expected, acidify. However, acidification only lasts for fractions of a millisecond followed by a predominant alkalinization that summates during burst firing. In addition, we observed that opening the cleft to adjacent spaces greatly alleviates the extent of $\mathrm{pH}$ disturbances accompanying neurotransmission.

\section{RESULTS}

\section{Imaging data show that the Drosophila NMJ synaptic cleft alkalinizes during activity}

The NMJ of Drosophila larvae is characterized by axonal swellings (boutons) making multiple synapses with a highly elaborated postsynaptic membrane [28]. Our ability to target $\mathrm{pH}$ sensitive fluorescent proteins to the outside surface of either pre- or postsynaptic membranes has enabled us to monitor pH changes within the synaptic cleft (Fig. 1A-B) [14, 29]. Without exception, the change in $\mathrm{pH}$ in response to a single AP $\left(\Delta \mathrm{pH}_{\mathrm{AP}}\right)$ is a rapid alkalinizing transient (Fig. 1C). The average $\Delta \mathrm{pH}_{\mathrm{AP}}$ is $\sim 0.025$ log units, peaking $\sim 50 \mathrm{~ms}$ after the nerve impulse, and decaying with a time course of $\sim 140 \mathrm{~ms}$ [14]. The suppression of all signs of pH change upon the addition of $7 \mathrm{mM}$ glutamic acid [Fig. 1C; which causes postsynaptic glutamate receptor desensitization [30]], or when $\mathrm{Ca}^{2+}$ is omitted from the bath saline (data not shown), led us to conclude that $\mathrm{Ca}^{2+}$ entry to the postsynaptic muscle and its subsequent extrusion by PMCA drives cleft alkalinization [14]. The change in $\mathrm{pH}$ in response to a train of stimuli $\left(\Delta \mathrm{pH}_{\text {train }}\right)$, intended to simulate the axon's activity during a peristaltic body-wall contraction, was well in excess of $\Delta \mathrm{pH}_{\mathrm{AP}}$ (Fig. 1D) and was similarly occluded by the presence of glutamate or absence of $\mathrm{Ca}^{2+}$ (data not shown). Our broad interpretation of the ion fluxes that drive a single AP evoked alkaline transient is sketched in Figure 1E.

\section{The NMJ is characterized by a narrow cleft and high PMCA activity}

In an attempt to reconcile our empirical data with both the release of $\mathrm{H}^{+}$from SVs and reports of ASIC activation at conventional glutamatergic synapses, we proceeded to a theoretical treatment of $\mathrm{pH}$ dynamics inspired by a previous numerical modeling approach [31]. As a first step, we measured critical distances at the synapse to establish geometrical constraints. Synaptic boutons form multiple AZs, readily visualized through immunohistochemistry (Fig. 2A). 
PMCA is heavily concentrated in the postsynaptic folds, and, while its presynaptic localization cannot be distinguished from the postsynaptic immunofluorescence signal, $\mathrm{Ca}^{2+}$ imaging studies have demonstrated the critical role of PMCA in extruding presynaptic $\mathrm{Ca}^{2+}$ in addition to postsynaptic $\mathrm{Ca}^{2+}[32,33]$. AZ spacing has been quantified in numerous EM studies indicating an average spacing of $\sim 0.8 \mu \mathrm{m}$ in $3^{\text {rd }}$ instar larvae [34-36]. In contrast, there are few reports of cleft width, thus we examined thin sections through larval $3^{\text {rd }}$ instar NMJs on muscle fibers \#6/7, 13 and 12. We defined cleft width as the distance between the outer-leaflet of the postsynaptic compartment and the outer-leaflet of the presynaptic compartment, yielding an average width of $13.5 \pm 0.4 \mathrm{~nm}$ (Fig. 2B-E). These values are generally consistent with other measurements made at the $3^{\text {rd }}$ instar NMJ [17 $\pm 1 \mathrm{~nm}$; [37]), with measurements via EM tomography in $2^{\text {nd }}$ instar larvae prepared through high-pressure freeze freeze-substitution [15.9 $\pm 0.1 \mathrm{~nm}$; [38]], and with reconstructions of super-resolved synaptic proteins [39]. Our EM examination also revealed that close apposition of the postsynaptic membrane often extends no further than $\sim 0.4$ $\mu \mathrm{m}$ from either side of the center of each $\mathrm{AZ}$ (arrow) before opening out into the interstitial space of the SSR (Fig. 2D). This can also be observed in previously published images of chemically fixed NMJs [36, 40].

\section{An overview of the computational model}

The geometry of our model is shown in Figure 2F-H, along with the identity of some of the molecular species and their relative movement. Briefly, we approximate the cleft as a gap between two infinite planes, each plane representing the outer face of the pre- and postsynaptic compartment. We define the center of the $A Z$ as the site of exocytosis. Once the acidic contents of a SV are released into the cleft, both Glu and ATP titrated with $\mathrm{H}^{+}$, diffuse throughout the cleft, becoming more dilute while releasing $\mathrm{H}^{+}$that react with bicarbonate and phosphate buffers. At pre- and postsynaptic compartments, the PMCA mediates the exchange of $\mathrm{H}^{+}$in the cleft for $\mathrm{Ca}^{2+}$ in pre- and postsynaptic compartments. Using coupled reaction-diffusion equations, as shown in Equation 1, we calculate the spatio-temporal concentration of each of 12 species within the cleft. See Table 1 for the identity of all species. We denote the concentration of a particular species as function of the location, $r$, and time, $t$ by $c_{i}(r, t)$, where $i$ $=1$ to 12 . For example, the concentration of $\mathrm{H}^{+}$is denoted as $\left[\mathrm{H}^{+}\right]=\mathrm{c}_{1}(\mathrm{r}, \mathrm{t})$.

$$
\frac{\partial c_{i}}{\partial t}=\nabla \cdot\left(D_{i} \nabla c_{i}\right)+\phi_{i}+J_{i}+S_{i} .
$$


Each term on the right-hand side of Equation 1 is discussed, along with assumptions, in the Methods. Briefly, the first term $D_{i}$ captures Fick's law of diffusion for each species; the diffusion coefficient for species $i$. The second term $\phi_{i}$ is the reaction term of species $i$, representing the production and consumption of that species as given in Equations 9-20 in the Methods. The third term, $J_{i}$ denotes the extrusion of $\mathrm{H}^{+}$from the cleft through PMCA which exchanges $\mathrm{Ca}^{2+}$ with $\mathrm{H}^{+}$while maintaining electroneutrality, i.e., $2 \mathrm{H}^{+}$for $\mathrm{Ca}^{2+}$. The last term $S_{i}$ represents the source term of each species.

\section{Cleft acidification is substantial, but fleeting}

The model was first used to explore cleft $\mathrm{pH}$ at the site of exocytosis where, under nearly all conditions, it revealed a deep but short-lasting acid transient (red trace, Fig. 3A). With bicarbonate present at $19 \mathrm{mM}$, facilitated by medium CA activity (CA; 600 nominal units), cleft $\mathrm{pH}$ plunged to 5.5 within microseconds of exocytosis. Perhaps the most surprising result was the ephemeral nature of cleft acidification. Even without bicarbonate or phosphate in the cleft, acidic transients "evaporated" within $500 \mu$ s through diffusion alone (Fig. 3B). When both buffering systems were enabled, cleft acidification was extinguished within only $50 \mu \mathrm{s}$.

Equidistant between the site at which exocytosis occurs and the site at which the cleft gives way to the SSR, bicarbonate buffering greatly ameliorated the depth of the acidic transients and total phosphate buffering of $1 \mathrm{mM}$ almost extinguished them (Fig. $\mathbf{3 C}$ ). At the site of release, the cleft invariantly acidified to the same $\mathrm{pH}$ as the SV lumen, independent of buffering conditions. Similarly, assumptions about SV loading in a range of 1,500 to 8,000 glutamate molecules, with or without co-loaded ATP at $100 \mathrm{mM}$ (610 molecules), were not influential with regard to the depth of acidification at the site of release (Fig. 3D). The time course of exocytosis has been estimated to be less than $100 \mu$ s [41, 42] but changing the time course of Glu release in this realm $(0.1-100 \mu \mathrm{s})$ has little influence on the depth of acidification or the rate at which the cleft recovers to neutral (Fig. 3E\&F). These data indicate that cleft acidification is inevitable at the site of exocytosis, and that it is of sufficient magnitude and duration to activate ASICs [43, 44]. Understandably, signs of cleft acidification terminating within fractions of a millisecond will be missed by imaging systems sampling at rates as slow as $~ 10 \mathrm{~ms}$ per frame $(100 \mathrm{~Hz}$, Fig. 1C) or $2 \mathrm{~ms}$ per line $(500 \mathrm{~Hz},[14])$.

\section{$\mathrm{Ca}^{2+}$ pumping across membranes alkalinizes the cleft}


An exploration of cleft $\mathrm{pH}$ for time periods beyond SV exocytosis required that PMCA activity be incorporated into the model and this revealed cleft alkalinization consistent with our empirical data (Fig. 4A-D). With bicarbonate present at $19 \mathrm{mM}$, and a "medium" level of CA activity [similar to conditions used in Fig, 1C\&D, and throughout Stawarski et al., (2020)], PMCA mediated exchange of cleft $\mathrm{H}^{+}$for cytosolic $\mathrm{Ca}^{2+}$ resulted in cleft alkalinization up to 7.45 , from a baseline of $7.20(\Delta \mathrm{pH} \sim 0.25)$, peaking $\sim 50 \mathrm{~ms}$ after exocytosis of a single SV. Cleft alkalinization begins at a very low rate once PMCA commences on the presynaptic plasma membrane and this can be seen in Figure 4D, right panel (\#), prior to exocytosis ( $\dagger$ ). Alkalinization accelerates as the activity of postsynaptic PMCA comes online [Fig. 4B\&C (right panels; arrows) and Fig. 4D ( $\psi())$ ]. The extent of alkalinization was sensitive to the degree of CA facilitation and almost extinguished by the presence of $1 \mathrm{mM}$ total phosphate. $\mathrm{A} \Delta \mathrm{pH}$ of 0.25 is much greater than estimates made from empirical data (0.02; Fig.1C; [14]), but empirical estimates rely on a signal-averaging technique that occludes estimates of $\Delta \mathrm{pH}$ at individual AZs (Illustrated in Fig. 6). We and others have previously established that the average probability of release from the AZs along these terminals is $\sim 0.11[45,46]$. Therefore, as the empirical estimate of 0.025 was generated from groups of AZs where exocytosis occurs with a probability of only $\sim 0.11, \Delta \mathrm{pH}$ for a single $\mathrm{AZ}$ undergoing exocytosis might be recalculated as $0.23(1 / 0.11$ $x$ 0.025), consistent with the displacement predicted by the model $(\sim 0.25)$. While cleft alkalinization does not reach magnitudes as great as acidification during exocytosis, the model shows that it persists for several orders of magnitude longer.

\section{Synapse morphology has a powerful influence on cleft pH}

While motor neuron axon terminals are buried in the muscle at the Drosophila NMJ, the cleft never-the-less opens out into voids within the post-synaptic folds, i.e. within the SSR. This space represents a large extracellular volume in close contact with a large area of muscle plasma membrane. Here we used the model to explore the role of the SSR in cleft $\mathrm{pH}$ homeostasis. The 12 ionic species considered in this model are restricted to move and react within the cleft, but for several exceptions: $\mathrm{CO}_{2}$ is allowed to diffuse freely across membranes, while $\mathrm{Ca}^{2+}$ and $\mathrm{H}^{+}$can move across membranes via VGCCs and GluRs $\left(\mathrm{Ca}^{2+}\right)$ and PMCA $\left(\mathrm{Ca}^{2+}\right.$ in exchange for $2 \mathrm{H}^{+}$). The consequences of not allowing species to exchange with the SSR 0.4 $\mu \mathrm{m}$ distant from the release site is shown in Fig. 5. Providing CA is present to support the buffering provided by $19 \mathrm{mM}$ bicarbonate, $\mathrm{pH}$ can recover to neutral after SV exocytosis. However, below a certain threshold of CA activity ( 500 nominal units), pH becomes unstable 
as the PMCA extrudes $\mathrm{H}^{+}$to an extent where PMCA will begin to stall only milliseconds after activation ( $\mathrm{pH} \sim 8.8$ ) (Fig. 5A). Distance from the site of release has little consequence (Fig. 5B). Time to stall is greatly abbreviated if the free movement of $\mathrm{CO}_{2}$ is prevented (Fig. 5C-D), as cleft $\mathrm{pH}$ becomes unstable in tens of microseconds, an outcome that can be slowed but not prevented by phosphate buffering. Blockage of species exchange with the SSR, or the free movement of $\mathrm{CO}_{2}$, has little impact on the magnitude of cleft acidification, and only a moderate effect on the duration of acidification (Fig. S4).

\section{Cleft alkalinization will summate at high frequencies}

As the cleft acidifies for such a short period ( $<1 \mathrm{~ms})$ it is highly unlikely that the axon would fire at a rate rapid enough ( $>1 \mathrm{kHz}$ ) for vestiges of acidification to persist in the cleft until the arrival of a subsequent AP. Alkalinization, however, is relatively prolonged, in which case vestiges of alkalinization might persist between APs. The model was used to examine the axon firing frequencies at which alkalinization begins to summate at an AZ (Fig. 6). Contrary to the expectation given by the buildup of alkalinization in Figure 1D, the model showed no signs of $\mathrm{pH}$ summation at individual AZs until axon firing well exceeded its native frequency of $21 \mathrm{~Hz}$. This counterintuitive result is a function of $\mathrm{pH}$ change being insulated between $\mathrm{AZs}$ and the probabilistic nature of neurotransmitter release. Release occurs with an average probability of only $\sim 0.11$ at these AZs [45, 46], in which case, although APs arrive in the presynaptic terminal at $21 \mathrm{~Hz}$, release events occur at an average rate of $2.3 \mathrm{~Hz}(21 \times 0.11)$ at any particular AZ. Insufficient alkalinization persists in the cleft when release occurs at only $2.3 \mathrm{~Hz}$, i.e. with an interval of $435 \mathrm{~ms}$ between release events. At axon firing frequencies beyond $\sim 40 \mathrm{~Hz}$ alkalinization summates at individual AZs (Fig. 6D-E). At $40 \mathrm{~Hz}$, the "average" AZ would release at $\sim 4.4 \mathrm{~Hz}(40 \times 0.11)$, i.e. once every $\sim 230 \mathrm{~ms}$, and at this rate $7 \%$ of the alkaline transient persists from the previous event. To the extent that fictive firing rates represent axon firing rates during locomotion, these axons fire at a rate below the threshold required to obtain a "boost" from a gain mechanism that exploits cleft alkalinization.

\section{DISCUSSION}

This study was driven by the cognitive dissonance created by recent imaging data showing alkalinization without a trace of acidification at conventional glutamatergic synapses [14], despite numerous studies that have demonstrated ASIC activation at conventional 
glutamatergic synapses. Our computational approach addresses this paradox and makes the following conclusions:

i. A degree of acidification is inevitable at the site of exocytosis at conventional glutamate synapses, although the time course is $<<1 \mathrm{~ms}$.

ii. Phosphate buffering has the capacity to almost entirely extinguish acidic transients at and above physiological levels ( 1 mM in humans; unknown in Drosophila), but bicarbonate buffering has little impact on the acid spike.

iii. Assumptions regarding the degree to which SVs are filled with Glu, and the time course of fusion pore opening, have little impact on the acid spike. Interestingly, co-loading with ATP substantially enhances the acidic spike.

iv. PMCA-mediated cleft alkalinization is systematically diminished by increasing CA activity, as observed empirically, and although it is almost entirely extinguished by $1 \mathrm{mM}$ phosphate in the open cleft, phosphate is far less influential in a closed cleft.

v. Cleft morphology, specifically, continuity with a neighboring void, is essential for controlling PMCA-mediated alkalinization, as cleft $\mathrm{pH}$ homeostasis will "fail" below a certain level of CA activity. The ability of $\mathrm{CO}_{2}$ to cross membranes gives greater power to bicarbonate buffering over phosphate buffering wherever cleft volume is restricted.

vi. Conditions for the summation of alkaline transients at individual AZs, from one AP to the next, would require either higher axon firing frequencies than those observed to date, or higher AZ release probabilities.

Ultimately the paradox is resolved, as it was previously anticipated [47] that "clefts harbor exceedingly rapid acidic transients at the level of microdomains", but that "detecting such rapid events with $\mathrm{pH}$ imaging would require sampling rates of $\sim 10 \mathrm{kHz}$ and knowledge of when release occurs at a particular release site to allow signal averaging."

The claim that acidification is inevitable at the site of exocytosis requires some qualification. The Drosophila NMJ cleft is exceedingly narrow $(13.5 \mathrm{~nm})$, but even if the distance was doubled [it is $28 \pm 9 \mathrm{~nm}$ at the rat Calyx of Held [48]] the consequence is minimal, as our model still shows cleft equilibration with SV pH (5.5) but with $1 / 2$-width of acidification somewhat diminished (from 0.123 to $0.080 \mathrm{~ms}$ ). Phosphate buffering has the greatest impact on the acid spike, with $1 \mathrm{mM}$ total phosphate halving it's depth and greatly reducing its $1 / 2$-width (from 0.123 to $0.006 \mathrm{~ms}$ ). It should be noted that $\mathrm{HPO}_{4}{ }^{2-}$ is only present at $0.5 \mathrm{mM}$ in our model, with $\mathrm{H}_{2} \mathrm{PO}_{4}{ }^{-}$ present at $0.5 \mathrm{mM}$. This can be put into context with inorganic phosphate levels in our blood ( $1 \mathrm{mM}$ ), which confers phosphate buffering of $\sim 0.8 \mathrm{mM} \mathrm{HPO}^{2-}$ and $\sim 0.2 \mathrm{mM} \mathrm{H}_{2} \mathrm{PO}_{4}^{-}$, when 
adjusted for a $\mathrm{pH}$ of 7.4 rather than 7.2 used here. Considering the activity coefficients of these ions, as much as $4 \mathrm{mM}$ phosphate would need to be added to a physiological saline such as ours to accomplish this sort of phosphate buffering power [49]. We should emphasize that the open boundary condition used here, i.e. access to an infinite buffer reservoir at a distance of 0.4 $\mu \mathrm{m}$, is ideal, whereas it is likely that there will be greater impediment to exchange at clefts in vivo. Certainly, the other ideal boundary condition of a closed cleft greatly curtails the ability of phosphate to dampen alkalinization. To the extent that an acid spike is not extinguished by the buffering system, an acid spike on the order of only 0.1-0.5 ms is well able to activate ASICs $[43,44]$. The capacity of phosphate buffering to tune transduction between SV exocytosis and ASIC activation therefore provides an intriguing window into a possible mechanism of action linking either hypophosphatemia or hyperphosphatemia with associated neurological disorders $[50,51]$.

While the likely presence of acidic microdomains can resolve the paradox, it is the alkaline signal that captured our attention, as it's integral is $\sim 3$ orders of magnitude larger. Unlike the acid transient, the slow alkaline transient is likely to persist from one AP to the next during a train of APs. However, as pointed out in Figure 6, this impression is misleading, as empirical data collected from groups of $A Z s$ (>>9) do not represent $\mathrm{pH}$ change at individual $\mathrm{AZs}$ that release with an average probability of 0.11 . The axon would have to fire at a frequency of $40 \mathrm{~Hz}$ or greater (double the axon's native firing frequency of $21 \mathrm{~Hz}$ ) before the "average" AZ would release at a rate where alkaline transients persisted from one release event to the next. The significance of transients persisting is that it allows for the summation of $\mathrm{pH}$ change at an $\mathrm{AZ}$, thus providing a mechanism for activity-dependent potentiation of release through the $\mathrm{pH}$ sensitivity of exposed synaptic proteins. Nevertheless, for the following reasons we are not ready to relinquish the possibility of such a gain mechanism. First, as at many other NMJs, release probability at the Drosophila NMJ is quite heterogeneous between AZs [52, 53], in which case any AZ with a probability twice the average, e.g. 0.22, could be potentiated at frequencies marginally over the native firing frequency. Secondly, the native firing frequency was quantified in restrained animals where the fictive locomotion representing peristaltic contractions was drawn out ten-fold, raising the question of whether firing frequency during each contraction was underestimated relative to a freely-behaving animal. Lastly, the model was only extrapolated to examine the potentiation of a second release event relative to the first - due to concerns about extrapolating the model well beyond assumptions made for individual release events. It seems reasonable to think that alkaline transient summation might proceed in a supralinear fashion as buffers deplete faster than they can be replenished in the synaptic cleft. Some support for the latter two points comes from the trans-cuticle imaging data of Stawarski et 
al., 2020, where cleft alkaline transients exceeded 1 log unit at some nerve terminals in the intact animal.

Perhaps the most surprising result was the finding of the necessity to "ventilate" the synapse to allow neurotransmitters to escape and exchange buffering entities with a larger volume. Part of the effect was likely a consequence of limitations of the model, where the movement of species beyond $\mathrm{Ca}^{2+}, \mathrm{H}^{+}$and $\mathrm{CO}_{2}$ across membranes was not accommodated. For instance, the model did not allow for Glu reuptake or bicarbonate movement across membranes, and all proton movement across membranes was confined to exocytosis and the exchange of $2 \mathrm{H}^{+}$for $\mathrm{Ca}^{2+}$ by PMCA. Despite these shortcomings, it seems unlikely that the depth of the $\mathrm{pH}$ spike would have been ameliorated by further sophistication of the model, such was the speed of the phenomenon. Furthermore, although the alkaline transient was primarily the product of PMCA activity, and heavily dependent on the level of CA activity, the effect of closing access to the voids of the SSR was robust. Both acidification and alkalinization events highlight the dynamic $\mathrm{pH}$ microenvironment within nervous tissue, and the limitations of $\mathrm{pH}$ homeostasis. Just as there are limitations to $\mathrm{Ca}^{2+}$ entry from the synaptic cleft [54], the density of synapses and their morphology might be limited by a need to accommodate $\mathrm{pH}$ transients and $\mathrm{pH}$ homeostatic mechanisms.

\section{MATERIALS AND METHODS}

\section{Experimental:}

pH imaging and Immunohistochemistry:

The experimental techniques and equipment used here were identical to those used by [14]. The fluorescent $\mathrm{pH}$ reporter pHusion-Ex was expressed in muscle fibers using the 24B-GAL4 [55] (Fig.1A). pHusion-Ex consists of superecliptic pHluorin with an N-terminal lgG $\kappa$ secretion signal linked to FusionRed with a C-terminal transmembrane sequence from the human plateletderived growth factor receptor (hPDGFR) [14]. Alexa Fluor 647 dextran 10,000 MW (AF647; D22914, Life Technologies) was forward-filled into motor nerve terminals using the technique described in [56] (Fig. 1 B). Female Drosophila $3^{\text {rd }}$ instar larvae were fillet dissected in Schneider's insect medium and transferred to HL6 physiological solution for live imaging [57]. Nerves to the hemisegment of interest were not cut except when an axon was forward-filled. Images of the live NMJ were collected on a Nikon AR1 laser-scanning confocal microscope using a $60 \times 1.2$ NA water-immersion apochromat Nikon objective (Fig. 1B). This confocal, and the wide-field imaging system described below, were controlled by Nikon NIS-Elements 
software. 16-bit images were subsequently converted to 8-bit for assembly into figures using Canvas X software (ACD Systems).

Changes in pHusion-Ex fluorescence (ratio) were calculated from pairs of images collected on a Nikon Eclipse FN1 microscope fitted with a 100 X 1.1 NA water-immersion objective using an Andor TuCam beam-splitter to direct emission wavelengths to two separate Andor iXon3 EMCCD cameras. Fluorophores were excited using a SPECTRA-X light source and images were collected at rates of either 94 pairs of images per second (Fig. 1C), or 10 pairs of images per second (Fig. 1D). Images were analyzed offline using ImageJ and the fluorescence ratio of pHusion-Ex was compared to the calibration of Stawarski et al., (2020) to yield values of $\mathrm{pH}$ change.

For the purposes of immunohistochemistry, fillet dissected preparations were fixed with Bouins solution for 1 minute before subsequent processing as described by Stawarski et al. 2020. The following antibodies were used: $1^{\circ}$ : nc82 (1:200) (mouse) from DSHB Hybridoma Bank (supernatant) and rabbit anti-PMCA, a gift from Dr. Gregory Lnenicka at SUNY Albany (1:200); $2^{\circ}$ : goat anti-mouse AF488 (1:500) (Invitrogen, A-11001), and donkey anti-rabbit Cy5 $(1: 200)$ (Jackson ImmunoResearch). Preparations were mounted under glass coverslips in SlowFade Gold (Invitrogen, S36937) and imaged using a 100 X 1.3 NA Olympus oil objective.

\section{Electron microscopy:}

Female Drosophila $3^{\text {rd }}$ instar larvae were filet dissected and fixed for $1 \mathrm{hr}$ with ice cold $3 \%$ paraformaldehyde and 2.5\% glutaraldehyde made up in 100 mM Sørensen's phosphate buffer (PB; pH 7.4) containing $2 \mathrm{mM} \mathrm{CaCl}_{2}$. Following fixation, larvae were washed with $\mathrm{PB} 5 \times 2$ mins. Any remaining fixative was then quenched with a $20 \mathrm{mM}$ glycine solution for 5 mins on ice, then washed with PB $3 \times 2$ minutes. Larvae were incubated in $1 \%$ aqueous $\mathrm{OsO}_{4}$ for 30 mins at room temperature (RT), then the solution was replaced with aqueous $1.5 \%$ potassium ferrocyanide for another 30 mins in the dark at RT. Larvae were washed with water $3 \times 10$ mins. Larvae were incubated in aqueous $1 \%$ uranyl acetate for $1 \mathrm{hr}$ in the dark at RT, then washed. Larvae were dehydrated in an ascending ethanol series for 10 mins each $(30 \%, 50 \%, 70 \%$, $90 \%, 100 \%, 100 \%$ ), then $1: 1$ ethanol to acetone for 5 mins and $100 \%$ acetone for $2 \times 10$ mins. For resin infiltration, larvae were placed in a 3:1 solution of acetone to Durcupan ACM resin mixture (Sigma-Aldrich) for $2 \mathrm{hrs}, 1: 1$ acetone to resin for $2 \mathrm{hrs}$, and 1:3 acetone to resin overnight. Larvae were placed in $100 \%$ resin for $4 \mathrm{hrs}$ under vacuum, then flat embedded between slide glass and an aclar sheet (Electron Microscopy Sciences) and polymerized at 60 ${ }^{\circ} \mathrm{C}$ for 2 days. Embedded larvae were mounted on resin blocks, then sectioned at $50 \mathrm{~nm}$ and collected on TEM grids. Samples were observed with a Tecnai G2 Spirit transmission electron 
microscope (Thermo Fisher Scientific) at $100 \mathrm{kV}$, and images were acquired using a Veleta CCD camera (Olympus) operated by TIA software (Thermo Fisher Scientific). Cleft widths were measured from 12 active zones (AZs) across 5 NMJs from muscle 6/7, 13 and 12.

Measurements were taken every $30 \mathrm{~nm}$ along each $\mathrm{AZ}$ and measured as the distance between the outer leaflet of the bouton plasma membrane and the outer leaflet of the SSR plasma membrane.

\section{Theoretical:}

\section{Sections i-iv below address different aspects of the computational model.}

\section{i) Geometry}

Assuming, for simplicity that AZs form a square lattice with regular periodicity in the $x$ and $y$ axis, we can restrict the domain of the numerical calculations to a "primitive" cell of the square lattice and impose periodic boundary conditions on the concentration of all the species, $\mathrm{c}_{\mathrm{i}}(\mathrm{x}, \mathrm{y}, \mathrm{z}, \mathrm{t})$ Table 1. The periodic boundary conditions dictate that $\mathrm{c}_{\mathrm{i}}(\mathrm{x}, \mathrm{y}, \mathrm{z}, \mathrm{t})=$ $c_{i}(x+m \times L, y+n \times L, z, t)$, where $m$ and $n$ are integers and $L$ is the distance between the centers of two primitive cells along either the $\mathrm{x}$ or $\mathrm{y}$ axis. The height of the primitive cell (13.5 $\mathrm{nm}$ ) was determined to be substantially less than its lateral extent (800 nm) (Fig. 2C-H), allowing us to neglect the $z$ dependence of the concentration fields, and treat Eq. 1 (see Results) as a two-dimensional problem. In our numerical computations, we impose two distinct boundary conditions. The first, based on our observations from electron microscopy (EM) images, where each primitive cell is connected to wide channels at its outer edges (Fig. 2B-D), informs a Dirichlet boundary condition. These channels may be viewed as an infinite reservoir of buffers, which implies that the concentration of all the species at the edges of the AZs may be taken to be constant throughout neuronal activity, i.e., $c_{i}(r=R, t)=$ const. The second boundary condition, represents a Neumann boundary condition, where we assume that there is no net flux of any species at the edge of the primitive cell; which implies that at the edges of AZs, $\left[\mathrm{dc}_{\mathrm{i}}(\mathrm{r}, \mathrm{t}) / \mathrm{dr}\right]_{\mathrm{r}=\mathrm{L}}=0$. Although there is no way to accurately determine the correct boundary conditions for the cleft, we believe that the Dirichlet boundary condition is more representative of the Drosophila NMJ. Indeed, as we show below, the results of our simulation using the Dirichlet boundary condition are largely in agreement with the experimental data. However, applying the Neumann boundary condition shows that the $\mathrm{pH}$ does not settle to the baseline in the time scale observed in the experiments unless we assume the $\mathrm{CO}_{2}$ concentration is constant in the cleft (ideal scenario where $\mathrm{CO}_{2}$ diffuses freely across membranes bounding the cleft) and the facilitation by carbonic anhydrase (CA) is above a certain threshold. Lastly, for both boundary conditions we assume azimuthal symmetry about the release site, which we take to be the 
origin of the primitive cell. Therefore, the concentration fields are a function of the radial distance away from the origin. In effect, the problem was reduced from a three-dimensional to a one-dimensional problem. To preserve the area of the primitive cell, we take its radius to be $\mathrm{R}=$ $\mathrm{L} / \sqrt{\pi}$, which gives the same area/volume for the primitive cell. Note that we assume azimuthal symmetry to simplify numerical calculations but verified that errors coming from edge effects are negligible.

\section{ii) Diffusion}

We start with the diffusion term of Eq. 1 for species $i$ and write it in polar coordinates, with the assumption of azimuthal symmetry as:

$$
\nabla \cdot\left(D_{i} \nabla c_{i}\right)=D_{i}\left(\frac{\partial^{2} c_{i}}{\partial r^{2}}+\frac{1}{r} \frac{\partial c_{i}}{\partial r}\right),
$$

where the diffusion coefficient is assumed to be constant throughout the cleft. Each of species 1-12 is identified in Table 1.

Table 1. Identity of all molecular species accommodated by Eq. 1.

\begin{tabular}{|l|l|l|}
\hline$\left[\mathrm{H}^{+}\right]=\mathrm{c}_{1}(\mathrm{r}, \mathrm{t})$ & {$\left[\mathrm{HCO}_{3}^{-}\right]=\mathrm{c}_{2}(\mathrm{r}, \mathrm{t})$} & {$\left[\mathrm{H}_{2} \mathrm{CO}_{3}\right]=\mathrm{c}_{3}(\mathrm{r}, \mathrm{t})$} \\
\hline$\left[\mathrm{CO}_{2}\right]=\mathrm{c}_{4}(\mathrm{r}, \mathrm{t})$ & {$\left[\mathrm{H}_{2} \mathrm{PO}_{4}^{-}\right]=\mathrm{c}_{5}(\mathrm{r}, \mathrm{t})$} & {$\left[\mathrm{HPO}_{4}^{2-}\right]=\mathrm{c}_{6}(\mathrm{r}, \mathrm{t})$} \\
\hline$\left[\mathrm{H}_{2} \mathrm{Glu}\right]=\mathrm{c}_{7}(\mathrm{r}, \mathrm{t})$ & {$\left[\mathrm{HGlu}^{-}\right]=\mathrm{c}_{8}(\mathrm{r}, \mathrm{t})$} & {$\left[\mathrm{Glu}^{2-}\right]=\mathrm{c}_{9}(\mathrm{r}, \mathrm{t})$} \\
\hline$\left[\mathrm{H}_{2} \mathrm{ATP}^{2-}\right]=\mathrm{c}_{10}(\mathrm{r}, \mathrm{t})$ & {$\left[\mathrm{HATP}^{3-}\right]=\mathrm{c}_{11}(\mathrm{r}, \mathrm{t})$} & {$\left[\mathrm{ATP}^{4-}\right]=\mathrm{c}_{12}(\mathrm{r}, \mathrm{t})$} \\
\hline
\end{tabular}

To implement our model numerically, we first employ the method of lines to discretize Eq. 2 in space and then divide the area of interest $(0 \leq r \leq R)$ into n concentric circles. Here, the value of $\mathrm{n}$ is chosen with the purpose of being able to run the simulation within a reasonable time (1015 minutes, $n=57$ ). To apply the boundary conditions numerically, we use the same method as that described in $[31,58]$ for both innermost (the release point) and outermost shell (the edge of primitive cell), with the exception that the outermost shell has two possibilities as discussed in the geometry section. The details of the finite element discretization and boundary conditions for the numerical calculations can be found in the Appendix. All the species are assumed to be initially at equilibrium (just before SV exocytosis) and are homogeneously distributed in the cleft. The initial values for the concentrations can be found in Table 3, for details on calculations see the buffers section. Diffusion coefficients, listed in Table 2 are measured in water, but in our 
simulations we use the effective diffusion coefficient $\left(D^{*}=D / \gamma^{2}\right)$ where $\gamma$ is the tortuosity of the environment [59], and is assumed to be 1.5 for the synaptic cleft [60-62].

\section{iii) Buffers}

The second term in Eq. 1 represents chemical reactions of all the species in our model, i.e., buffering, which plays a vital part in the $\mathrm{pH}$ regulation $[1,63,64]$. We consider the following reactions for bicarbonate, phosphate, glutamate (Glu), and ATP:

$$
\begin{aligned}
& \mathrm{H}^{+}+\mathrm{HCO}_{3}^{-} \rightleftharpoons{ }_{\mathrm{k}_{2,1}}^{\mathrm{k}_{1,2}} \quad \mathrm{H}_{2} \mathrm{CO}_{3} \quad \rightleftharpoons_{\mathrm{k}_{3,2}}^{\mathrm{k}_{2,3}} \quad \mathrm{CO}_{2}+\mathrm{H}_{2} \mathrm{O} \\
& \mathrm{H}^{+}+\mathrm{HPO}_{4}^{2-} \rightleftharpoons \mathrm{k}_{5,4}^{\mathrm{k}_{4,5}} \quad \mathrm{H}_{2} \mathrm{PO}_{4}^{-} \\
& \mathrm{H}^{+}+\mathrm{HGlu}^{-} \rightleftharpoons \mathrm{k}_{7,6}^{\mathrm{k}_{6,7}} \quad \mathrm{H}_{2} \mathrm{Glu}, \\
& \mathrm{H}^{+}+\mathrm{Glu}^{2-} \rightleftharpoons \mathrm{k}_{\mathrm{g}, 8}^{\mathrm{k}_{8,9}} \quad \mathrm{HGlu}^{-} \\
& \mathrm{H}^{+}+\mathrm{ATP}^{4-} \rightleftharpoons \mathrm{k}_{11,10}^{\mathrm{k}_{10,11}} \quad \mathrm{HATP}^{3-}, \\
& \mathrm{H}^{+}+\mathrm{HATP}^{3-} \rightleftharpoons \mathrm{k}_{13,12} \mathrm{k}_{12,13} \quad \mathrm{H}_{2} \mathrm{ATP}^{2-} .
\end{aligned}
$$

Where Eq. 3 and 4 denote the bicarbonate and phosphate buffering reactions, respectively. Eq. 5 and 6 describe the protonation of different species of Glu and Eq. 7 and 8 describe protonation of different species of ATP. We note that all reactions, except for the hydration/dehydration of $\mathrm{CO}_{2}$ in $E q .3$, are extremely fast when compared to the time scale of the diffusion of all the species [31]. Here, with the exception of the hydration/dehydration of $\mathrm{CO}_{2}$ in Eq. 3, we choose the rates of reactions from Eqs. 3-8 to be as fast as possible with the result that the concentration dynamics of all the species are limited by diffusion $[22,31,65,66]$. The rates of these reactions can be found in Table 2. Note that we have ignored the reaction $\mathrm{HCO}_{3}^{-} \rightleftharpoons \mathrm{CO}_{3}^{2-}+\mathrm{H}^{+}$(which is related to Eq. 3), because it occurs at a high pH well outside the $\mathrm{pH}$ range of the experiments we are modeling. Furthermore, the reaction $\mathrm{H}_{2} \mathrm{CO}_{3} \rightleftharpoons \mathrm{CO}_{2}+\mathrm{H}_{2} \mathrm{O}$ is normally very slow in comparison to the rest of the reactions, but by adding CA enzymatic 
activity, the reaction gets faster and may render this reaction relevant. Rather than including it in our reaction diffusion equations, we simply implement this facilitation by augmenting the rate of hydration/dehydration of $\mathrm{CO}_{2}$ to a larger value $\left(\mathrm{En}_{\mathrm{acc}}\right)[31,59,67]$, as found in Table 2 . Thus, we write the mass reaction rate equations as:

$$
\begin{aligned}
& \phi_{1}=-\mathrm{k}_{1,2}\left[\mathrm{H}_{+}\right]\left[\mathrm{HCO}_{3}^{-}\right]+\mathrm{k}_{2,1}\left[\mathrm{H}_{2} \mathrm{CO}_{3}\right]-\mathrm{k}_{4,5}\left[\mathrm{H}^{+}\right]\left[\mathrm{HPO}_{4}^{2-}\right]+\mathrm{k}_{5,4}\left[\mathrm{H}_{2} \mathrm{PO}_{4}^{-}\right]-\mathrm{k}_{6,7}\left[\mathrm{HGlu}^{-}\right]\left[\mathrm{H}^{+}\right] \\
& +\mathrm{k}_{7,6}\left[\mathrm{H}_{2} \mathrm{Glu}\right]-\mathrm{k}_{8,9}\left[\mathrm{Glu}^{2-}\right]\left[\mathrm{H}^{+}\right]+\mathrm{k}_{9,8}\left[\mathrm{HGlu}^{-}\right]-\mathrm{k}_{10,11}\left[\mathrm{H}^{+}\right]\left[\mathrm{ATP}^{4-}\right] \\
& +\mathrm{k}_{11,10}\left[\mathrm{HATP}^{3-}\right]-\mathrm{k}_{12,13}\left[\mathrm{H}^{+}\right]\left[\mathrm{HATP}^{3-}\right]+\mathrm{k}_{13,12}\left[\mathrm{H}_{2} \mathrm{ATP}^{2-}\right] \\
& \phi_{2}=-\mathrm{k}_{1,2}\left[\mathrm{H}_{+}\right]\left[\mathrm{HCO}_{3}^{-}\right]+\mathrm{k}_{2,1}\left[\mathrm{H}_{2} \mathrm{CO}_{3}\right] \\
& \phi_{3}=\mathrm{k}_{1,2}\left[\mathrm{H}_{+}\right]\left[\mathrm{HCO}_{3}^{-}\right]-\mathrm{k}_{2,1}\left[\mathrm{H}_{2} \mathrm{CO}_{3}\right]-\mathrm{k}_{2,3}\left[\mathrm{H}_{2} \mathrm{CO}_{3}\right]+\mathrm{k}_{3,2}\left[\mathrm{CO}_{2}\right] \\
& \phi_{4}=-\mathrm{k}_{3,2} \mathrm{CO}_{2}+\mathrm{k}_{2,3}\left[\mathrm{H}_{2} \mathrm{CO}_{3}\right] \\
& \phi_{5}=-\mathrm{k}_{5,4}\left[\mathrm{H}_{2} \mathrm{PO}_{4}^{-}\right]+\mathrm{k}_{4,5}\left[\mathrm{H}^{+}\right]\left[\mathrm{HPO}_{4}^{2-}\right] \\
& \phi_{6}=-\mathrm{k}_{4,5}\left[\mathrm{H}^{+}\right]\left[\mathrm{HPO}_{4}^{2-}\right]+\mathrm{k}_{5,4}\left[\mathrm{H}_{2} \mathrm{PO}_{4}^{-}\right] \\
& \phi_{7}=-\mathrm{k}_{7,6}\left[\mathrm{H}_{2} \mathrm{Glu}\right]+\mathrm{k}_{6,7}\left[\mathrm{H}^{+}\right]\left[\mathrm{HGlu}^{-}\right] \\
& \phi_{8}=\mathrm{k}_{7,6}\left[\mathrm{H}_{2} \mathrm{Glu}\right]-\mathrm{k}_{6,7}\left[\mathrm{H}^{+}\right]\left[\mathrm{HGlu}^{-}\right]-\mathrm{k}_{9,8}\left[\mathrm{HGlu}^{-}\right]+\mathrm{k}_{8,9}\left[\mathrm{Glu}^{2-}\right]\left[\mathrm{H}^{+}\right] \\
& \phi_{9}=-\mathrm{k}_{8,9}\left[\mathrm{H}^{+}\right]\left[\mathrm{Glu}^{2-}\right]+\mathrm{k}_{9,8}\left[\mathrm{HGlu}^{-}\right] \\
& \phi_{10}=-\mathrm{k}_{13,12}\left[\mathrm{H}_{2} \mathrm{ATP}^{2-}\right]+\mathrm{k}_{12,13}\left[\mathrm{H}^{+}\right]\left[\mathrm{HATP}^{3-}\right] \\
& \phi_{11}=\mathrm{k}_{10,11}\left[\mathrm{ATP}^{4-}\right]\left[\mathrm{H}^{+}\right]-\mathrm{k}_{11,10}\left[\mathrm{HATP}^{3-}\right]-\mathrm{k}_{12,13}\left[\mathrm{HATP}^{3-}\right]\left[\mathrm{H}^{+}\right]+\mathrm{k}_{13,12}\left[\mathrm{H}_{2} \mathrm{ATP}^{2-}\right] \\
& \phi_{12}=-\mathrm{k}_{10,11}\left[\mathrm{H}^{+}\right]\left[\mathrm{ATP}^{4-}\right]+\mathrm{k}_{11,10}\left[\mathrm{HATP}^{3-}\right]
\end{aligned}
$$

To calculate the initial concentrations of the species above, which can be found in Table 3, we simply assume that all the species are at an equilibrium before the $\operatorname{AP}\left(\phi_{\mathrm{i}}=0\right)$. Applying this equilibrium condition to Eq. 9-20 allows us to obtain the initial concentration of each of the 
species. Because the extracellular concentrations of Glu and ATP are in the $\mu M$ range $[68,69]$, they do not play a significant role in buffering and we assume their steady state concentrations to be zero.

\section{iv) Extrusion}

The third term in Eq. 1, $J_{i}$, denotes the extrusion of $\mathrm{H}^{+}$from the cleft through the PMCA which exchanges $\mathrm{Ca}^{2+}$ for $2 \mathrm{H}^{+}$. Note that the only non-zero term, $J_{1}$, is calculated from a kinetic model of the PMCA based on the Michaelis-Menten equation. Although several $\mathrm{H}^{+}$exchangers such as $\mathrm{Na}^{+} / \mathrm{H}^{+}$and $\mathrm{Cl}^{-} / \mathrm{H}^{+}$on the plasma membrane have the potential to remove $\mathrm{H}^{+}$from the cleft, it is the PMCA activity which is responsible for cleft alkalinization [14, 20]. As previously mentioned, PMCA is vital for the clearance of $\mathrm{Ca}^{2+}$ from both the pre-and postsynaptic compartments during synaptic activity $[32,33]$. Most of the $\mathrm{Ca}^{2+}$ which enters the cytosolic compartment is bound to mobile and immobile $\mathrm{Ca}^{2+}$ buffers, but subsequently intercepted by the PMCA, $\mathrm{Na}^{+} / \mathrm{Ca}^{2+}$ exchanger (NCX), mitochondria and the endoplasmic reticulum (ER); the latter two acting as $\mathrm{Ca}^{2+}$ traps. In an electroneutral process, the PMCA exchanges one $\mathrm{Ca}^{2+}$ for $2 \mathrm{H}^{+}$in the cleft, thereby driving $\mathrm{pH}$ changes in the cleft [70]. To model this process at pre- and postsynaptic compartments, we make use of the Michaelis-Menten kinetics for a one-substrate enzymecatalyzed reaction, where PMCA is taken to be the enzyme and $\mathrm{Ca}^{2+}$ as the substrate. For simplicity, we assume that both the pre- and postsynaptic compartments are modeled with the same process, but with different densities of PMCA and peaks in $\mathrm{Ca}^{2+}$ concentration. Thus, we write the chemical reaction for this process as [71, 72]:

$$
\mathrm{PMCA}_{\mathrm{P}_{0}}+\mathrm{Ca}^{2+} \rightleftharpoons_{\mathrm{k}_{2}}^{\mathrm{k}_{1}} \mathrm{PMCA}_{\mathrm{P}_{1}} \cdot \mathrm{Ca}^{2+} \rightarrow{ }^{\mathrm{k}_{3}} \mathrm{PMCA}_{\mathrm{P}_{0}}
$$

where PMCA can take on two conformational states denoted by $\mathrm{P}_{0}$ and $\mathrm{P}_{1}$, where $\mathrm{P}_{0}$ has a high affinity for $\mathrm{Ca}^{2+}$ and $\mathrm{P}_{1}$ has a low affinity for $\mathrm{Ca}^{2+}$. $\mathrm{P}_{0}$ is localized at the intracellular leaflet of both pre- and postsynaptic compartments while $\mathrm{P}_{1}$ is exposed to the cleft at the extracellular leaflet of both the pre- and postsynaptic compartments [71]. Note that there is a turnover between $P_{0}$ and $P_{1}$ with a rate of $k_{3}$. Because PMCA is continually operating, even in the absence of an AP, there should be a steady leakage of $\mathrm{Ca}^{2+}$ into the pre- and postsynaptic compartments in order to achieve a steady state condition [73]. At steady state, we assume the rate at which the $\mathrm{H}^{+}$are removed from the cleft by PMCA equals the rate of leakage of $\mathrm{H}^{+}$from the pre- and postsynaptic compartment to the cleft. In other words, we neglect the baseline $\mathrm{H}^{+}$extrusion from the cleft. 
The Michaelis-Menten equation gives the rate at which $\mathrm{H}^{+}$are being extruded from the cleft by PMCAs [73]:

$$
\begin{gathered}
\mathrm{J}_{1}(\mathrm{r}, \mathrm{t})=-\frac{2 \text { A. } v_{\text {max }, \text { pre }}}{\mathrm{V}} \frac{\left[\mathrm{Ca}^{2+}\right]_{\text {pre }}}{\mathrm{K}_{\mathrm{m}}+\left[\mathrm{Ca}^{2+}\right]_{\text {pre }}}-\frac{2 \text { A.v } v_{\text {max,post }}}{\mathrm{V}} \frac{\left[\mathrm{Ca}^{2+}\right]_{\text {post }}}{\mathrm{K}_{\mathrm{m}}+\left[\mathrm{Ca}^{2+}\right]_{\text {post }}}+\mathrm{J}_{1, \mathrm{~s} . \mathrm{s}}, \\
\mathrm{J}_{1, \mathrm{~s} . \mathrm{s}}=\frac{2 \mathrm{~A} \cdot v_{\text {max,pre }}}{\mathrm{V}} \frac{\left[\mathrm{Ca}^{2+}\right]_{\text {pre,s.s }}}{\mathrm{K}_{\mathrm{m}}+\left[\mathrm{Ca}^{2+}\right]_{\text {pre,s.s }}}+\frac{2 \mathrm{~A} \cdot v_{\text {max,post }}}{\mathrm{V}} \frac{\left[\mathrm{Ca}^{2+}\right]_{\text {post,s.s }}}{\mathrm{K}_{\mathrm{m}}+\left[\mathrm{Ca}^{2+}\right]_{\text {post,s.s }}}
\end{gathered}
$$

where $\mathrm{K}_{\mathrm{m}}=\left(\mathrm{k}_{2}+\mathrm{k}_{3}\right) / \mathrm{k}_{1}$ is the half-maximal activating concentration, $v_{\text {max,pre }}=\mathrm{n}_{\mathrm{pre}} \mathrm{k}_{3}$ and $v_{\text {max,post }}=\mathrm{n}_{\text {post }} \mathrm{k}_{3}$ are the maximal velocity of transport $\left[\frac{\mathrm{pmol}}{\mathrm{cm}^{2} . \mathrm{s}}\right]$ in pre- and postsynaptic compartments, respectively, $\mathrm{n}_{\text {pre }}$ and $\mathrm{n}_{\text {post }}$ are the density of PMCA at pre- and postsynaptic compartment, respectively, $\mathrm{A}$ is the area, and $\mathrm{V}$ the volume of the primitive cell. In Eq. 22-b $\left[\mathrm{Ca}^{2+}\right]_{\text {pre,s.s }}$ and $\left[\mathrm{Ca}^{2+}\right]_{\text {post,s.s }}$ are steady-state concentrations of $\mathrm{Ca}^{2+}$ at pre- and post-synaptic compartments, respectively and $\mathrm{J}_{1, \mathrm{s.s}}$, which is a constant, is the steady-state extrusion of $\mathrm{H}^{+}$ from the cleft. Note also that $J_{1}$ has no spatial dependence as we assume that the PMCA is distributed uniformly on pre- and postsynaptic compartments and that $\mathrm{Ca}^{2+}$ is homogeneously distributed in the cleft. Note that in Eq. $22-\mathrm{a},\left[\mathrm{Ca}^{2+}\right]_{\text {pre }}$ and $\left[\mathrm{Ca}^{2+}\right]_{\text {post }}$ are concentration of $\mathrm{Ca}^{2+}$ at pre- and postsynaptic compartments, respectively at each time and the "2" accounts for the fact that $2 \mathrm{H}^{+}$exchange for $\mathrm{Ca}^{2+}$. Furthermore, $\frac{\left[\mathrm{Ca}^{2+}\right]}{\mathrm{K}_{\mathrm{m}}+\left[\mathrm{Ca}^{2+}\right]}$ can be interpreted as the fraction of PMCA on pre- and postsynaptic compartments that would exchange $2 \mathrm{H}^{+}$with $\mathrm{Ca}^{2+}$ to the cleft at time $t$.

To proceed, both $\left[\mathrm{Ca}^{2+}\right]_{\text {pre }}$ and $\left[\mathrm{Ca}^{2+}\right]_{\text {post }}$ are required as a function of time. Ideally, we would implement $\mathrm{Ca}^{2+}$ as a separate species in our reaction-diffusion equation along with all its buffers and organelles that take up $\mathrm{Ca}^{2+}$ and release it in an intermittent fashion on pre- and postsynaptic compartment. However, this would make the model unreasonably complicated for the following three reasons: 1) complex geometry of the postsynaptic compartment, 2) lack of information on the location and density of $\mathrm{Ca}^{2+}$ permeable channels, 3) the complexity of mechanisms which regulate intracellular $\mathrm{Ca}^{2+}$ concentration that needs the implementation of Monte Carlo methods. For simplicity, we postulate that both $\left[\mathrm{Ca}^{2+}\right]_{\text {pre }}$ and $\left[\mathrm{Ca}^{2+}\right]_{\text {post }}$ take the following form as a function of time: 


$$
\begin{gathered}
{\left[\mathrm{Ca}^{2+}\right]=\mu *\left[(1-\mathrm{s}(\mathrm{t})) *\left(1-\exp \left(-\left(\mathrm{t}-\mathrm{t}_{\mathrm{d}}\right) / \mathrm{t}_{\mathrm{r}}\right)\right) * \theta\left(\mathrm{t}-\mathrm{t}_{\mathrm{d}}\right)+\mathrm{s}(\mathrm{t}) * \exp \left(-\frac{\left(\mathrm{t}-\mathrm{t}_{\mathrm{p}}\right)}{\left.\left.\tau_{\mathrm{Ca}^{2+}}\right)\right]+}\right.\right.} \\
{\left[\mathrm{Ca}^{2+}\right]_{\text {s.s }}} \\
\mathrm{s}(\mathrm{t})=0.5+0.5 * \tanh \left(\left(\mathrm{t}-\mathrm{t}_{\mathrm{p}}\right) / \mathrm{b}\right)
\end{gathered}
$$

Where, $\theta(t)$ is the step function, and $t_{d}, t_{r}, t_{p}, \tau_{\mathrm{Ca}^{2+}}$ and $\mu$ are: latent time $\left(t<t_{d},\left[\mathrm{Ca}^{2+}\right]=\right.$ steady state $\mathrm{Ca}^{2+}$ concentration), tau of rise, time of peak, tau of decay, and maximum $\mathrm{Ca}^{2+}$ concentration, respectively. It is important to note that these parameters take on different values on the pre- and postsynaptic compartments of the cleft. This is because different $\mathrm{Ca}^{2+}$ entry and $\mathrm{Ca}^{2+}$ regulation mechanisms operate on either side. Therefore, $\left[\mathrm{Ca}^{2+}\right]_{\text {pre }}$ and $\left[\mathrm{Ca}^{2+}\right]_{\text {post }}$ should have different kinetics and time courses. For example, in the presynaptic compartment, $\mathrm{Ca}^{2+}$ entry is through VGCCs, while on postsynaptic compartment it is through GluRs. This causes $t_{p}$ of the presynaptic compartment to be much shorter than that of the postsynaptic compartment. The values of $t_{d}, t_{p}, t_{r}, \tau_{\mathrm{Ca}^{2+}}$ and $\mu$ for the presynaptic compartment are approximated from [45], while for the postsynaptic compartment $t_{d}, t_{p}, t_{r}$ are approximated from measurements made from two-electrode voltage clamp (TEVC) recordings in our laboratory (data not shown). The value for $\tau_{\mathrm{Ca}^{2+}}$ in the postsynaptic compartment is obtained from [32] and $\mu$ is adjusted to capture experimental results (for more details, see the numerical simulation section). All the parameters of PMCA and $\mathrm{Ca}^{2+}$ concentration can be found in Table 5. As depicted in Figure S1, the time course of Eq. 23 is such that for $t<t_{d},\left[\mathrm{Ca}^{2+}\right]$ is at the steady state $\mathrm{Ca}^{2+}$ concentration and then rises quickly to reach a peak between time $t_{d}<t<t_{p}$, then for $t>t_{p}$ the concentration decays exponentially. The features of these time courses are generally reflected in data from $\mathrm{Ca}^{2+}$ imaging experiments $[32,45,57]$.

\section{v) Source Terms}

The last term in Eq. 1, $\mathrm{S}_{\mathrm{i}}$, represents the source term of each species. The only non-zero terms of $S_{i}$ are $i=1,7,8,9,10,11,12$. In our model, we assume each $A Z$ releases only one $S V$ in addition to a complete fusion of the SV to the plasma membrane, i.e., a SV releases all of its contents. We also assume SVs contain Glu, ATP, and free $\mathrm{H}^{+}$. For the kinetics of release of Glu and ATP from the SVs, the number of molecules of each one of these three species in SVs at 
any time has the form $N_{i}(t)=N_{i, 0} \exp \left(-\frac{t}{\tau_{i, f}}\right)$, where $\tau_{i, f}$ is the time constant of fusion and release, and $\mathrm{N}_{\mathrm{i}, 0}$ is the total number of molecules of species $\mathrm{i}$ in a SV before the release. Therefore, $S_{i}(t)=-\left(1 / V_{S V}\right) d_{i}(t) / d t=S_{i, 0} \exp \left(-\frac{t}{\tau_{i, f}}\right)$, where $V_{S V}$ is the volume of a $S V$ and $\mathrm{S}_{\mathrm{i}, 0}=\frac{\mathrm{N}_{\mathrm{i}, 0}}{\tau_{\mathrm{i}, \mathrm{f}} \mathrm{V}_{\mathrm{SV}}}$. Previous measurements from high-resolution TEVC recordings of miniature excitatory junctional currents (mEJCs) suggest that the rise time of a mEJC is less than $100 \mu \mathrm{s}$ [41]. Therefore, most of the Monte Carlo models that use the kinetics of SV release assume the release of Glu and ATP to be instantaneous [72]. Here, we will also use a very small value as $\tau_{\mathrm{i}, \mathrm{f}}=1 \mu \mathrm{s}$, except where indicated otherwise.

Given that $\mathrm{N}_{\mathrm{i}, 0}$ is dependent on the $\mathrm{pH}$ of the SV lumen, for the species $\mathrm{i}=1$, we calculate it by using the $\mathrm{pH}$ of the SV (pH 5.5). Whereas, for $\mathrm{i}=7,8,9$ and $\mathrm{i}=10,11,12$, which represent the different Glu and ATP species, respectively, we use titration plots (Fig. S2). In aqueous solutions, glutamic acid has four different charged and uncharged variants denoted by $\mathrm{H}_{3} \mathrm{Glu}^{+}, \mathrm{H}_{2} \mathrm{Glu}, \mathrm{HGlu}^{-}$, $\mathrm{Glu}^{2-}$. In our numerical model, we ignore $\mathrm{H}_{3} \mathrm{Glu}^{+}$because this variant only becomes relevant when $\mathrm{pH}$ is lower than 4.5-5 [74]. If we assume that before release, the glutamic acid molecules in a SV are at equilibrium, their concentrations can be obtained using Eqs. 15, 16 and 17, by setting $\phi_{\mathrm{i}}=0$, with the constraint that $T$, the total number of Glu molecules (including all its variants) divided by the volume of SV, must be a constant. Therefore,

$$
\begin{gathered}
{\left[\mathrm{H}_{2} \mathrm{Glu}\right]=\frac{\mathrm{k}_{6,7}\left[\mathrm{H}^{+}\right]\left[\mathrm{HGlu}^{-}\right]}{\mathrm{k}_{7,6}},} \\
{\left[\mathrm{Glu}^{2-}\right]=\frac{\mathrm{k}_{9,8}\left[\mathrm{HGlu}^{-}\right]}{\mathrm{k}_{8,9}\left[\mathrm{H}^{+}\right]},} \\
{\left[\mathrm{H}_{2} \mathrm{Glu}\right]+\left[\mathrm{HGlu}^{-}\right]+\left[\mathrm{Glu}^{2-}\right]=\mathrm{T},}
\end{gathered}
$$

and therefore, we find

$$
\left[\mathrm{HGlu}^{-}\right]=\frac{\mathrm{T}}{\frac{\mathrm{k}_{6,7}}{\mathrm{k}_{7,6}}\left[\mathrm{H}^{+}\right]+\frac{\mathrm{k}_{9,8}}{\mathrm{k}_{8,9}} \frac{1}{\left[\mathrm{H}^{+}\right]}+1}
$$


For example, for $\mathrm{i}=7,8,9$ if we assume to have a total of 8000 Glu molecules [75] at a SV pH of 5.5 [76], we have $\mathrm{N}_{7,0} \approx 426, \mathrm{~N}_{8,0} \approx 7574, \mathrm{~N}_{9,0}=0\left(426 \mathrm{H}_{2} \mathrm{Glu}, 7574 \mathrm{HGlu}^{-}, 0 \mathrm{Glu}^{2-}\right)$.

For $\mathrm{i}=10,11,12$, we can apply the same calculations as done for Glu above, to obtain the proportion of each species of ATP at different pH (Fig. S2B). The acid-base behavior of ATP has been studied in [77] and assume the ionic strength to be $0.1 \frac{\mathrm{mol}}{\mathrm{L}}$.

Next, we require the total number of ATP molecules in SVs. Unfortunately, there is no information in the literature about the number of ATP molecules in a single glutaminergic SV. To solve this, we assume the number of ATP molecules is either zero, or that it is dictated by the osmotic pressure. This means that if a SV contains mostly ATP and Glu, the summation of total Glu concentration and ATP in the SV is equal to the osmotic pressure of the containing environment $(\sim 350 \mathrm{mOsm})$. As a result, one of our simulations is for the hypothetical scenario of $250 \mathrm{mM}$ glutamate with $100 \mathrm{mM}$ of ATP. Even though it seems that SVs can hold neurotransmitters above the cytosolic osmotic pressure [78], our assumption is only for simulating the effect of ATP on acid transients. It is worthwhile to mention that by comparing the titration figures of Glu and ATP, we observe that for the same concentration of both species, ATP will release substantially more $\mathrm{H}^{+}$than Glu when both are released from an environment of $\mathrm{pH} 5.5$ into an environment where they can equilibrate to a pH 7.2 (Fig. S2A-B).

Table 2 (Kinetic rates, diffusion coefficients, and assorted constants)

\begin{tabular}{|c|c|c|c|c|c|}
\hline Parameter & Value & Source & Parameter & Value & Source \\
\hline $\mathrm{k}_{1,2}$ & $4.15 * 10^{16} \frac{1}{\mathrm{mM} . \mathrm{s}}$ & {$[31]$} & $\mathrm{k}_{13,12}$ & $10^{10} \frac{1}{\mathrm{~s}}$ & $\begin{array}{l}\text { Chosen to achieve } \\
\text { equilibrium }\end{array}$ \\
\hline $\mathrm{k}_{2,1}$ & $1 * 10^{16} \frac{1}{\mathrm{~s}}$ & $\begin{array}{l}\text { Chosen to achieve } \\
\text { equilibrium }\end{array}$ & $\mathrm{D}_{\mathrm{H}^{+}}$ & $8.69 * 10^{-5} \frac{\mathrm{cm}^{2}}{\mathrm{~s}}$ & [31] \\
\hline $\mathrm{k}_{2,3}$ & $10.9631 \frac{1}{\mathrm{~s}}$ & [31] & $\mathrm{D}_{\mathrm{HCO}_{3}^{-}}$ & $1.11 * 10^{-5} \frac{\mathrm{cm}^{2}}{\mathrm{~s}}$ & [31] \\
\hline $\mathrm{k}_{3,2}$ & $0.0302 \frac{1}{\mathrm{~s}}$ & [31] & $\mathrm{D}_{\mathrm{H}_{2} \mathrm{CO}_{3}}$ & $1.11 * 10^{-5} \frac{\mathrm{cm}^{2}}{\mathrm{~s}}$ & [31] \\
\hline $\mathrm{k}_{4,5}$ & $1.584 * 10^{14} \frac{1}{\mathrm{mM} . \mathrm{s}}$ & [79] & $\mathrm{D}_{\mathrm{CO}_{2}}$ & $1.71 * 10^{-5} \frac{\mathrm{cm}^{2}}{\mathrm{~s}}$ & [31] \\
\hline $\mathrm{k}_{5,4}$ & $1 * 10^{10} \frac{1}{\mathrm{~s}}$ & $\begin{array}{l}\text { Chosen to achieve } \\
\text { equilibrium }\end{array}$ & $\mathrm{D}_{\mathrm{H}_{2} \mathrm{PO}_{4}^{-}}$ & $1.56 * 10^{-5} \frac{\mathrm{cm}^{2}}{\mathrm{~s}}$ & [31] \\
\hline$\frac{\mathrm{k}_{7,6}}{\mathrm{k}_{6,7}}$ & $5.62 * 10^{-2} \frac{1}{\mathrm{mM}}$ & [80] & $\mathrm{D}_{\mathrm{HPO}_{4}^{2-}}$ & $1.56 * 10^{-5} \frac{\mathrm{cm}^{2}}{\mathrm{~s}}$ & [31] \\
\hline$\frac{\mathrm{k}_{9,8}}{\mathrm{k}_{8,9}}$ & $2.14 * 10^{-7} \mathrm{mM}$ & [80] & $\mathrm{D}_{\mathrm{Glu}}$ & $0.76 * 10^{-5} \frac{\mathrm{cm}^{2}}{\mathrm{~s}}$ & [81] \\
\hline$E_{\text {acc }}$ & 600 & Adjusted & $\mathrm{D}_{\mathrm{Glu}^{-}}$ & $0.76 * 10^{-5} \frac{\mathrm{cm}^{2}}{\mathrm{~s}}$ & [81] \\
\hline
\end{tabular}




\begin{tabular}{|c|c|l|c|c|c|}
\hline $\mathrm{k}_{6,7}$ & $10^{10} \frac{1}{\mathrm{~s}}$ & $\begin{array}{l}\text { Chosen to achieve } \\
\text { equilibrium }\end{array}$ & $\mathrm{D}_{\mathrm{Glu}^{2-}}$ & $0.76 * 10^{-5} \frac{\mathrm{cm}^{2}}{\mathrm{~s}}$ & [81] \\
\hline $\mathrm{k}_{8,9}$ & $10^{10} \frac{1}{\mathrm{~s}}$ & $\begin{array}{l}\text { Chosen to achieve } \\
\text { equilibrium }\end{array}$ & $\mathrm{D}_{\mathrm{ATP}^{4-}}$ & $0.71 * 10^{-5} \frac{\mathrm{cm}^{2}}{\mathrm{~s}}$ & {$[82]$} \\
\hline$\frac{\mathrm{k}_{11,10}}{\mathrm{k}_{10,11}}$ & $3.412 * 10^{-4} \mathrm{mM}$ & {$[77]$} & $\mathrm{D}_{\mathrm{ATP}^{3-}}$ & $0.71 * 10^{-5} \frac{\mathrm{cm}^{2}}{\mathrm{~s}}$ & {$[82]$} \\
\hline $\mathrm{k}_{11,10}$ & $10^{10} \frac{1}{\mathrm{~s}}$ & $\begin{array}{l}\text { Chosen to achieve } \\
\text { equilibrium }\end{array}$ & $\mathrm{D}_{\mathrm{ATP}^{2-}}$ & $0.71 * 10^{-5} \frac{\mathrm{cm}^{2}}{\mathrm{~s}}$ & {$[82]$} \\
\hline$\frac{\mathrm{k}_{12,13}}{\mathrm{k}_{13,12}}$ & $\frac{1}{\mathrm{mM}}$ & {$[77]$} & $\lambda$ & 1.5 & {$[62]$} \\
\hline
\end{tabular}

Table 3 (Initial and steady-state concentrations in the cleft)

\begin{tabular}{|c|c|l|c|c|l|}
\hline Parameter & Value & Source & Parameter & Value & Source \\
\hline $\mathrm{pH}$ & 7.2 & {$[14]$} & {$\left[\mathrm{HGlu}^{-}\right]$} & 0 & Assumed \\
\hline$\left[\mathrm{H}^{+}\right]$ & $63 \mathrm{nM}$ & Calculated from $\mathrm{pH}$ & {$\left[\mathrm{Glu}^{2-}\right]$} & 0 & Assumed \\
\hline$\left[\mathrm{HCO}_{3}^{-}\right]$ & $19 \mathrm{mM}$ & {$[14]$} & {$\left[\mathrm{H}_{2} \mathrm{PO}_{4}^{-}\right]$} & $0.5 \mathrm{mM}$ & Calculated \\
\hline$\left[\mathrm{H}_{2} \mathrm{CO}_{3}\right]$ & $0.005 \mathrm{mM}$ & Calculated & {$\left[\mathrm{HPO}_{4}^{2-}\right]$} & $0.5 \mathrm{mM}$ & Assumed \\
\hline$\left[\mathrm{CO}_{2}\right]$ & $1.8 \mathrm{mM}$ & Calculated & {$\left[\mathrm{H}_{2} \mathrm{ATP}^{2-}\right]$} & 0 & Assumed \\
\hline$\left[\mathrm{H}_{3} \mathrm{Glu}\right]$ & 0 & Assumed & {$\left[\mathrm{HATP}^{3-}\right]$} & 0 & Assumed \\
\hline$\left[\mathrm{H}_{2} \mathrm{Glu}\right]$ & 0 & Assumed & {$\left[\mathrm{ATP}^{4-}\right]$} & 0 & Assumed \\
\hline
\end{tabular}

Table 4 (Source parameters in the SV lumen)

\begin{tabular}{|c|c|l|l|c|l|}
\hline Parameter & Value & Source & Parameter & Value & Source \\
\hline $\mathrm{pH}$ & 5.5 & {$[76]$} & $\mathrm{N}_{0, \text { glutamate }}$ & 8000 & {$[75]$} \\
\hline$\left[\mathrm{H}^{+}\right]_{\text {free }}$ & $3.2 \mu \mathrm{M}$ & Calculated & {$\left[\mathrm{H}_{2} \mathrm{Glu}\right]_{\mathrm{SV}}$} & $69.97 \mathrm{mM}$ & Calculated \\
\hline$\tau_{\mathrm{f}}$ & $1 \mu \mathrm{s}$ & Assumed $[41]$ & {$\left[\mathrm{HGlu}^{-}\right]_{\mathrm{SV}}$} & $1242.9 \mathrm{mM}$ & Calculated \\
\hline $\mathrm{r}_{\mathrm{SV}}$ & $13.42 \mathrm{~nm}$ & {$[83]$} & {$\left[\mathrm{Glu}^{2-}\right]_{\mathrm{SV}}$} & 0 & Calculated \\
\hline $\mathrm{N}_{0, \mathrm{ATP}}$ & 610 & $\begin{array}{l}\text { Assumed (to arrive at } \\
100 \mathrm{mM} \text { total ATP in SV) }\end{array}$ & {$\left[\mathrm{HATP}^{-}\right]_{\mathrm{SV}}$} & $87.28 \mathrm{mM}$ & Calculated \\
\hline$\left[\mathrm{H}_{2} \mathrm{ATP}\right]_{\mathrm{SV}}$ & $3.47 \mathrm{mM}$ & Calculated & {$\left[\mathrm{ATP}^{2-}\right]_{\mathrm{SV}}$} & $9.35 \mathrm{mM}$ & Calculated \\
\hline
\end{tabular}


Table 5 (Extrusion parameters)

\begin{tabular}{|c|c|c|c|c|c|}
\hline Parameter & Value & Source & Parameter & Value & Source \\
\hline $\mathrm{K}_{\mathrm{m}}$ & $0.83 \mu \mathrm{M}$ & Adjusted $[72,73,84]$ & $\mathrm{k}_{3}$ & $100 \frac{1}{\mathrm{~s}}$ & [72] \\
\hline $\mathrm{n}_{\text {pre }}$ & $150 \frac{1}{\mu \mathrm{m}^{2}}$ & $\begin{array}{l}\text { Adjusted (from } \\
\text { glutamate experiment } \\
{[14] \text { ) }}\end{array}$ & $\mathrm{n}_{\text {post }}$ & $1750 \frac{1}{\mu \mathrm{m}^{2}}$ & Adjusted \\
\hline$\mu_{\text {pre }}$ & $0.4 \mu \mathrm{M}$ & [45] & $\mu_{\text {post }}$ & $2.5 \mu \mathrm{M}$ & Adjusted \\
\hline $\mathrm{t}_{\mathrm{d} \text {,pre }}$ & $0.5 \mathrm{~ms}$ & [85] & $\mathrm{t}_{\mathrm{d} \text {,post }}$ & $0.9 \mathrm{~ms}$ & [85] \\
\hline$t_{p, \text { pre }}$ & $1.5 \mathrm{~ms}$ & [85] & $t_{p, p o s t}$ & $39.3 \mathrm{~ms}$ & Our TEVC experiments \\
\hline $\mathrm{t}_{\mathrm{r}, \mathrm{pre}}$ & $0.2 \mathrm{~ms}$ & Adjusted & $t_{r, \text { post }}$ & $8 \mathrm{~ms}$ & Adjusted \\
\hline$b_{\text {pre }}$ & $0.5 \mathrm{~ms}$ & Adjusted [45] & $b_{\text {post }}$ & $10 \mathrm{~ms}$ & Adjusted \\
\hline$\tau_{\mathrm{Ca}^{2+}, \text { pre }}$ & $50 \mathrm{~ms}$ & [45] & $\tau_{\mathrm{Ca}^{2+}, \text { post }}$ & $50 \mathrm{~ms}$ & {$[32]$} \\
\hline$\mu_{\text {pre(train) }}$ & $1.2 \mu \mathrm{M}$ & [32] & 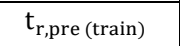 & $27 \mathrm{~ms}$ & Adjusted [57] \\
\hline$t_{d, p r e(t r a i n)}$ & $0.5 \mathrm{~ms}$ & Adjusted [45] & $\left.\mathrm{b}_{\text {pre(train }}\right)$ & $0.5 \mathrm{~ms}$ & Adjusted $[45,57]$ \\
\hline$t_{p, \text { pre(train) }}$ & $3 *\left(\frac{1000}{21}\right) \mathrm{ms}$ & [57] & $\tau_{\mathrm{Ca}^{2+}, \text { pre(train) }}$ & $68 \mathrm{~ms}$ & [57] \\
\hline
\end{tabular}

\section{vi) Numerical Simulation}

To numerically solve Eq. 1, we first use the method of lines to discretize Eq. 1 in space (semidiscretization). The origin of most values used are presented in Table 5. The resulting equations can be written in a matrix form with each element in the column vector representing the concentration of a particular species in each shell. After discretization, $n$ stiff ordinary differential equations (ODE) remain, requiring special solvers [31]. To numerically solve the problem we used MATLAB's ODE15s and a 16 core CPU - AMD Ryzen 3900X to run the code, where we set the relative and absolute tolerance to $10^{-10}$ to ensure scheme stability. Here, the output plots are restricted to $\mathrm{pH}$ vs time [31].

To test the utility of the model, we sought to test its numerical output against previously published empirical data [14]. However, to do so, we first had to recognize the mismatch between the model output, which generates cleft $\mathrm{pH}$ values for individual $\mathrm{AZs}$, and the empirical data which represents a quantification of pHusion-Ex fluorescence collected from entire boutons harboring dozens of AZs, most of which do not release neurotransmitter with each AP. These fluorescence signals were compared to a calibration where all AZs around a bouton were simultaneously immersed in a saline series representing $\mathrm{pH}$ standards [14]. Such a protocol could provide the correct calibration for individual AZs only if all AZs did the same thing at the same time during an AP, i.e. all released neurotransmitter. A probability of release of anything less than 1 will lead to an underestimate of $\mathrm{pH}$ change at an individual $\mathrm{AZ}$. Following in the 
footsteps of Stawarski et al. (2020), we examined the terminal of MN6/7-lb which houses AZs with an average probability of release of $\frac{1}{9}[45,46]$. If $9 \mathrm{AZs}$ are found at each bouton then the empirical data represent the fluorescence response of $1 \mathrm{AZ}$ firing at random, and this generates a $\Delta F / F$ signal of $1.94 \%$ [14]. As $\Delta F / F=\left(F_{\text {stim }}-F_{\text {rest }}\right) / F_{\text {rest }}$, we might recapitulate the fluorescence change at an individual $A Z$ by dividing $F_{\text {rest }}$ by 9 . This is because the $F_{\text {stim }}$ value represents an increase in fluorescence over an $F_{\text {rest }}$ value which is approximately 9 fold smaller than the value of the entire bouton. The new $\Delta \mathrm{F} / \mathrm{F}$ signal of $17.5 \%$ can be compared directly with the calibration and yields $\Delta \mathrm{pH} \approx 0.225$ for an individual $\mathrm{AZ}$, equivalent to a change in $\mathrm{pH}$ from 7.200 to 7.425 for an individual AZ. Also see Figure 6A-C.

As mentioned throughout the manuscript, the values of some of the parameters such as the density of the PMCA, $\mathrm{K}_{\mathrm{m}}$ of PMCA, $\mathrm{Ca}^{2+}$ concentration in postsynaptic microdomains where the PMCAs are located, and the concentration of ATP within glutamatergic SVs have eluded direct measurement at most synapses, not just at the Drosophila NMJ. For this reason, we drew on parameter values from multiple sources beyond the Drosophila NMJ, where all parameter values ultimately fell within a reasonable physiological range. Here we provide further explanation for a number of the parameters listed in Table 5. Starting with $v_{\max }$, we note that a quantitative determination has been extremely difficult [72]. To get an estimated value of $v_{\max }$ for Eq. 22, we require the values for $\mathrm{k}_{3}, \mathrm{n}_{\text {pre }}$ and $\mathrm{n}_{\text {post }}$. First, we assume that $\mathrm{k}_{3}$ on pre- and postsynaptic compartments are same with the value $\mathrm{k}_{3}=100 \frac{1}{\mathrm{~s}}$ [72], which leads to $\Delta \mathrm{pH}$ results consistent with our experimental data. If we use $\mathrm{k}_{3}=12 \frac{1}{\mathrm{~s}}[84,86]$, the resulting $\Delta \mathrm{pH}$ would be significantly lower than the predicted experimental data. In addition, as discussed in [87], it is possible that the value of $k_{3}$ measured in vitro is lower than the actual values of the PMCA of in vivo systems. Second, we need to know $n_{\text {pre }}$ and $n_{\text {post }}$. Unfortunately, no direct measurements at the Drosophila NMJ have been reported to date, where reported values range from $300-$ $4000\left[\frac{1}{\mu \mathrm{m}^{2}}\right][87,88]$. To estimate $n_{\text {pre }}$, we leveraged the experimental result where $7 \mathrm{mM}$ glutamic acid extinguishes alkalinization supplied by the postsynaptic compartment by desensitizing GluRs (Fig. 2H of [14]). Desensitization of GluRs prevents $\mathrm{Ca}^{2+}$ influx to the postsynaptic compartment. Therefore, as can be seen from Eq. 22, an absence of postsynaptic $\mathrm{Ca}^{2+}$ entry is synonymous with no removal of cleft $\mathrm{H}^{+}$by postsynaptic PMCA activity. Any resulting alkaline transient is the product of presynaptic PMCA activity alone. However, presynaptic PMCA activity was insufficient to generate a cleft alkaline transient that could be distinguished from the noise (Fig. $2 \mathrm{H}$ of [14]), i.e. it would need to be less than $\sim 0.0015$ log 
units. It is also important to note that the presence of $7 \mathrm{mM}$ glutamic acid is effective at buffering $\mathrm{H}^{+}$near neutral $\mathrm{pH}$, thus diminishing the amplitude of any alkaline transient generated by the presynaptic PMCA. Therefore, given that we are unable to detect a cleft alkaline transient solely from the presynaptic compartment as a consequence of the small signal in addition to the buffering of $7 \mathrm{mM}$ glutamic acid, we used the noise of the data acquired from these experiments to obtain an approximate value of $n_{\text {pre }}$. Here, we use $\sim 0.0015 \log$ units as maximum limit of alkalization rising from presynaptic for $n_{\text {pre }}$. We observed that a value of $150 \frac{1}{\mu \mathrm{m}^{2}}$ for $n_{\text {pre }}$ replicated the empirical data, i.e. an alkaline transient no greater than $0.0015 \mathrm{pH}$ units - in the presence of $7 \mathrm{mM}$ glutamate (Fig. S3). A value of $1750 \frac{1}{\mu \mathrm{m}^{2}}$ for $\mathrm{n}_{\text {post }}$ replicated the empirical data (Fig. S3). The corresponding values of $v_{\max }$ for pre- and postsynaptic sides are $v_{\max , \text { pre }}=$ $2.49 \frac{\mathrm{pmol}}{\mathrm{cm}^{2} . \mathrm{s}}$ and $v_{\text {max,pre }}=29.06 \frac{\mathrm{pmol}}{\mathrm{cm}^{2} . \mathrm{s}}$ respectively, whereas the value of $v_{\max }$ used in other models is in the range of $v_{\max }=0.2-400 \frac{\mathrm{pmol}}{\mathrm{cm}^{2} . \mathrm{s}}[73,89-92]$. Note: since PMCA activity obeys Michaelis-Menton kinetics and because the maximum ratio of activated PMCA is $\frac{\left[\mathrm{Ca}^{2+}\right] \text { peak }}{\left[\mathrm{Ca}^{2+}\right] \text { peak }+\mathrm{Km}}$, then for values of $0.4 \mu \mathrm{M} \mathrm{Ca}^{2+}$ pre, $2.5 \mu \mathrm{M} \mathrm{Ca}^{2+}$ post and $\mathrm{K}_{\mathrm{m}}=0.83$, the ratios for pre- and postsynaptic compartments will be $32 \%$ and $75 \%$. Clearly, the difference in $\mathrm{Ca}^{2+}$ concentration in the two compartments cannot solely explain the empirical data (specifically, Fig. 1C and Fig. S3) and the method above was required to solve for unknown PMCA densities in the pre- and postsynaptic compartments. A third parameter requiring explanation, also relevant to Eq. 22, is the value of $\mathrm{K}_{\mathrm{m}}$. As mentioned above, the expression, $\frac{\left[\mathrm{Ca}^{2+}\right]}{\mathrm{K}_{\mathrm{m}}+\left[\mathrm{Ca}^{2+}\right]}$, can be interpreted as the fraction of PMCA activated. However, if we choose a value of $K_{m}$ in Eq. 22 lower than $0.5 \mu \mathrm{M}$, it leads to a flat peak in $\mathrm{J}_{1}$ for the postsynaptic compartment. Consequently, a flat peak for alkalinization in the results of the simulation. Therefore, the value of $\mathrm{K}_{\mathrm{m}}$ is adjusted to a value of $0.8 \mu \mathrm{M}$, such that the kinetics and time course of $\Delta \mathrm{pH}$ is consistent with our experimental data. The value of $\mathrm{K}_{\mathrm{m}}$ used in other models ranges from $0.2 \mu \mathrm{M}$ to $3 \mu \mathrm{M}[73,84,87,90]$.

To bring physiological context to the model, where neurons fire in bursts resulting in repeated release from the same $A Z s$, we implemented a train of APs at $21 \mathrm{~Hz}$ in our simulations. An individual $A Z$ with release probability of 0.11 will fire at $21 \times 0.11=2.3 \mathrm{~Hz}$. The parameters of presynaptic $\mathrm{Ca}^{2+}$ concentration can be found in Table 5, where we have assumed it takes 4 nerve impulses to reach a plateau and remain constant until the last stimulus and then decay exponentially with $\tau=68$ ms. For simplicity, we have assumed that postsynaptic $\mathrm{Ca}^{2+}$ concentration for each $A Z$ is the same as a single AP. Given that we are working with stiff 
bioRxiv preprint doi: https://doi.org/10.1101/2021.06.30.450624; this version posted June 30, 2021. The copyright holder for this preprint (which was not certified by peer review) is the author/funder. All rights reserved. No reuse allowed without permission.

ODEs, the results of the MATLAB's ODE solvers do not have the same $d t$. In order to find the average of 9 AZs (Fig. 6C), we used MATLAB's 'pchip' to interpolate between data points. After creating the same $d t$ for all of the AZs, we found the average of all the AZs. 


\section{LEGENDS}

Figure 1. The cleft of the Drosophila NMJ alkalinizes during activity. (A) The pH sensitive pHusion-Ex probe can be targeted to the extracellular spaces of the NMJ as an anchor using a transmembrane domain. (B) When expressed in the muscle the probe is seen in the SSR that surrounds motor nerve terminal boutons (revealed here through forward-filling the live axon with AF647). (C) Cleft alkalinization can be seen in response to a single AP, providing signal averaging is used. Both traces represent the average of $100 \mathrm{APs}$ delivered at $1 \mathrm{~Hz}$. (D) Cleft alkalinization can be seen in response to a train of APs (without signal averaging) delivered at the neuron's native firing frequency $(21 \mathrm{~Hz})$. In $\mathrm{C}$ and $\mathrm{D}, \mathrm{NaHCO}_{3}$ is added to $15 \mathrm{mM}$ and continuously bubbled with carbogen; stabilizing at $\mathrm{pH}$ 7.2. No phosphate or zwitterionic buffers present. (E) Our interpretation of this phenomenon is summarized in a temporal series: In response to an $\mathrm{AP}, \mathrm{Ca}^{2+}$ entry to the pre-synaptic terminal triggers the exocytosis of glutamate, co-loaded ATP, and protons titrated by both. Activation of post-synaptic glutamate receptors allows $\mathrm{Ca}^{2+}$ entry to the pre-synaptic muscle. The PMCA extrudes $\mathrm{Ca}^{2+}$ from both pre- and postsynaptic compartments using protons as a counter-ion.

\section{Figure 2. The Drosophila NMJ synaptic cleft is very narrow, but continuous with an} adjacent void. (A) Fluorescent images of two proteins at the NMJ revealed by immunohistochemistry; Presynaptic Bruchpilot (Brp), defining the AZs, and PMCA found in both pre- and postsynaptic compartments. (B) An electron micrograph of a $50 \mathrm{~nm}$ section through the center of a presynaptic bouton and the surrounding muscle SSR. AZs, which are often marked by a "T-bar" extending into the cytosol from the pre-synaptic membrane (green arrow), can be found at a number of sites around the bouton's periphery. (C) An enlarged view of the AZ indicated by the green arrow in B. (D) Interpretation of the image in (C), emphasizing the location of the T-bar, the cleft, and the common observation that the cleft usually empties out into voids of the SSR $400 \mathrm{~nm}$ distant from the center of each AZ (see asterisk). (E) Plot of the width of the cleft (between outer leaflets of opposing plasma membranes) at NMJs on muscle fibers \#7/6, 13 and 12. Each point represents measurements at $12 \mathrm{AZs}$ at each of 5 boutons on each of the muscle fibers; mean \pm SEM. (F) Schematic of a cross-section of a bouton embedded within the muscle SSR, showing release into the cleft from 2 out of 5 AZs. (G) For computational purposes, the cleft can be treated as a continuous layer, sandwiched between the planes of two opposing membranes; represented here in cross section annotated with critical distances. (H) An expanded view of release and subsequent PMCA activity, emphasizing 
the location of PMCA activity and the location at which the cleft becomes continuous with the voids within the SSR.

Figure 3. The synaptic cleft shows substantial but brief acidification. (A) Output plots of the computational model. When 8,000 glutamate molecules are released into the cleft containing $19 \mathrm{mM}$ bicarbonate and a medium level of CA activity [enzymatic acceleration (En $\mathrm{n}_{\text {acc }}$ of 600 (nominal units)], the $\mathrm{pH}$ at the mouth of fusion pore drops to 5.5 (i.e. equilibrates with SV contents) within microseconds (deep red trace - corresponding to location of the deep red asterisk). The cleft then alkalinizes, reaching a peak of $\sim 7.45$ within $\sim 50 \mathrm{~ms}$, before decaying to the pre-stimulus baseline at $\mathrm{pH}$ 7.2. Midway between the fusion pore and access to the SSR (location of the black asterisk), both acidification and alkalinization are ameliorated in magnitude (black trace). (B-C) Bicarbonate buffering has little impact on cleft acidification at either the site of release or midway between the fusion pore and SSR; phosphate buffering, however, is very effective (1 mM total). (D) If SV loading is reduced to 1,500 glutamate so that it is isosmotic with the cytosol (250 mM), and co-loaded with 610 ATP molecules (100 mM; total $350 \mathrm{mM})$, the acid transient is similarly deep as when 8,000 glutamate is released. (E-F) The time course of fusion pore opening similarly has little impact on the depth of acidification over a range of 4 orders of magnitude ( $\tau=0.1-100 \mu \mathrm{s} ; 8,000$ glutamate). Bicarbonate buffering is $19 \mathrm{mM}$ in all scenarios except diffusion only. Fusion pore opening $(\tau)$ is $1 \mu \mathrm{s}$, except where indicated otherwise (E\&F).

Figure 4. The synaptic cleft shows moderate but long lived alkalinization. (A) Identical to figure $3 A$, the model output plots in panel A provide context for the detail of B-F. (B-C) show the minimal impact of bicarbonate buffering on cleft acidification caused by neurotransmitter release. The extended time-scale encompasses the transition point from acidification to alkalinization $(\psi)$ at $\sim 0.9 \mathrm{~ms}$ (when the impact of post-synaptic PMCA activity becomes apparent). (D) Left panel shows the first $80 \mathrm{~ms}$ after release, illustrating the shape of alkaline transient which does not decay until after post-synaptic $\mathrm{Ca}^{2+}$ entry ceases at $\sim 40 \mathrm{~ms}$. Right panel shows detail of the boxed section on the left. \# : cleft alkalinization as a result of presynaptic PMCA activity; † : cleft acidification as a result of exocytosis; @ : realkinization as a result of diffusion, buffering and pre-synaptic PMCA activity; $\psi$ : alkalinization as a result of preand post-synaptic PMCA activity. (E-F) Bicarbonate, and especially phosphate buffering (1 mM), is effective at ameliorating cleft alkalinization. Note: the 400 fold change in time base between B-C and E-F. 8,000 glutamate molecules released and $19 \mathrm{mM}$ bicarbonate buffering in all 
scenarios. Fusion pore opening $(\tau)$ is $1 \mu \mathrm{s}$. Medium and high CA activity are 600 and 2,000 $E n_{\text {acc }}$ nominal units, respectively. $\kappa$ indicates truncated acidic transients.

Figure 5. Synapse morphology has a powerful influence on cleft pH. (A-B) Output plots of the computational model showing the impact of preventing access from the synaptic cleft to the void of the SSR (note the location of asterisks in A vs B). The dashed line represents the control conditions, i.e. bicarbonate buffering in the presence of medium CA activity, full access to the SSR and membrane permeability to $\mathrm{CO}_{2}$. Low, medium and high CA activity are 100, 600 and 2,000 En acc nominal units, respectively. Note, because of the ability of $\mathrm{CO}_{2}$ to cross membranes, high CA activity is better able to buffer $\mathrm{pH}$ changes than medium CA activity in combination with $1 \mathrm{mM}$ total phosphate. When CA activity $\left(E n_{\text {acc }}\right)$ falls below $\sim 500$ nominal units cleft buffering fails. $\mathrm{pH} 8.8$ represents the $\mathrm{pH}$ at which the PMCA is expected to stall [33]. (C-D) Plots showing the impact of both preventing cleft access to the SSR, and preventing $\mathrm{CO}_{2}$ movement across membranes. Cleft pH buffering failed in all cases (note the location of asterisks in $\mathrm{C}$ vs D). 8,000 glutamate molecules released and $19 \mathrm{mM}$ bicarbonate buffering in all scenarios. Fusion pore opening $(\tau)$ is $1 \mu \mathrm{s} . \kappa$ indicates truncated acidic transients. Detail of acidic transients and first 80 $\mathrm{ms}$ of the alkaline transients are given in Figure S4.

\section{Figure 6. MNs must fire beyond usual rates before alkaline transients will summate at}

individual AZs. (A-C) A scheme which illustrates why $\mathrm{pH}$ reporter fluorescence summation from a bouton over multiple nerve impulses may not indicate $\mathrm{pH}$ transient summation at individual AZs. (A) Stylized representation of resting fluorescence of a cytosolic $\mathrm{Ca}^{2+}$ reporter (both sides of the synapse) and an extracellular $\mathrm{pH}$ reporter (muscle PM) at a single bouton of the NMJ. (B) Representation of the $\mathrm{Ca}^{2+}$ and $\mathrm{pH}$ responses to release from individual AZs over 10 APs; $\mathrm{Ca}^{2+}$ response are postsynaptic and $\mathrm{pH}$ responses are in the cleft. The $\mathrm{Ca}^{2+}$ reporter responses are shown to delineate the location of each releasing $A Z$. The average probability of release is $1 / 9$, and $9 \mathrm{AZs}$ have been illustrated responding sequentially around the periphery of a bouton. The images capture the maximal response; the time of image capture is represented with an arrow on the $\mathrm{pH}$ plots for each $\mathrm{AZ}$. The plots of $\mathrm{pH}$ change at each of the $\mathrm{AZs}$ are generated by the model (LHS ordinate). The images show the location of an AZ-delimited region-of-interest $(\mathrm{ROI})$ that would be expected to yield $\mathrm{pH}$ sensor transients $\left(\Delta \mathrm{F} / \mathrm{F}_{\text {rest }}\right)$ of the magnitude shown (RHS ordinate). C, Numerical summation of all $\mathrm{AZ} \mathrm{pH}$ plots in $\mathrm{B}$ yields a $\mathrm{pH}$ change for the entire bouton that is well below that of an $A Z$, but, unlike $p H$ at an individual $A Z$, it summates over multiple APs. The RHS ordinate shows the expected fluorophore transients 
$\left(\Delta \mathrm{F} / \mathrm{F}_{\text {rest }}\right)$ if the $\mathrm{ROI}$ encompassed the entire bouton containing the $9 \mathrm{AZs}$, and this is compatible with what is observed empirically (Fig. 1D). (D) Model generated plots of $\mathrm{pH}$ an individual $\mathrm{AZ}$ where one release event follows another after a defined interval. (E) A plot of the potentiation of the $2^{\text {nd }}$ alkaline transient relative to the $1^{\text {st }}$, across different axon firing frequencies and $A Z$ release frequencies. The vertical dotted line represents the average firing frequency for this motor neuron.

\section{Figure S1. The time course of changes in $\mathrm{Ca}^{2+}$ concentration in pre- and post-synaptic} compartments. (A) Stylized representations of changes in fluorescence of $\mathrm{Ca}^{2+}$ reporters on either side of the synaptic cleft responding to cytosolic $\mathrm{Ca}^{2+}$ changes associated with a presynaptic AP and the subsequent entry of $\mathrm{Ca}^{2+}$ into the postsynaptic muscle through GluR opposite a single presynaptic AZ. (B) Plots of the changes in cytosolic $\mathrm{Ca}^{2+}$ concentration over time on either side of the synapse $\left(\left[\mathrm{Ca}^{2+}\right]_{\text {pre }}\right.$ and $\left.\left[\mathrm{Ca}^{2+}\right]_{\text {post }}\right)$. These plots differ due to the different mechanisms responsible for $\mathrm{Ca}^{2+}$ entry and $\mathrm{Ca}^{2+}$ extrusion on different sides of the synapse. $\mathrm{Ca}^{2+}$ enters the pre-synaptic compartment through VGCCs over a period of $\sim 1 \mathrm{~ms}$ during the later stages of the presynaptic AP. $\mathrm{Ca}^{2+}$ enters the postsynaptic compartment over a more extended time-course ( $40 \mathrm{~ms}$ ) through GluR after neurotransmitter is released from the pre-synaptic terminal. Inset; detail of the first $10 \mathrm{~ms}$ after the arrival of the pre-synaptic AP.

Figure S2. Bjerrum plots for glutamate and ATP. (A) Glutamate is a polyprotic acid, with three protonation sites, and at any $\mathrm{pH}$ the quantity of each ionizable species may be expressed as the ratio of the concentration of that species to the total concentration of glutamate. i.e. the mole fraction. The number of $\mathrm{H}^{+}$that dissociate from glutamate after exocytosis can be calculated from the change in number of each species, and thus the change in net charge. (B) ATP has two protonation sites, and the same approach can be taken to calculate how many $\mathrm{H}^{+}$ dissociate from ATP after exocytosis.

\section{Figure S3. Substantiating presynaptic and postsynaptic PMCA density.}

(A-B) Output plots of the computational model demonstrating that the PMCA density values chosen for the pre- and postsynaptic membranes ( $n_{\text {pre }}$ and $n_{\text {post }}$, respectively) yield $\mathrm{pH}$ transients that are compatible with empirical data published by Stawarski et al., 2020. In the presence of $7 \mathrm{mM}$ glutamic acid, a PMCA density of $150 \frac{1}{\mu \mathrm{m}^{2}}$ on the presynaptic side replicated the empirical data, i.e. an alkaline transient of only $0.0019 \log$ units at the site of release $(\mathbf{A})$, and 0.0014 midway along the cleft $(\mathbf{B})$. In the presence of $7 \mathrm{mM}$ glutamate, a PMCA density of $1750 \frac{1}{\mu \mathrm{m}^{2}}$ on 
the postsynaptic side replicated the empirical data, i.e. an alkaline transient of 0.258 log units at the site of release $(\mathbf{A})$, and 0.181 midway along the cleft $(\mathbf{B})$. The legend at the bottom applies to all plots. $19 \mathrm{mM}$ bicarbonate and a medium level of CA activity is present under all conditions (600 En $\mathrm{n}_{\mathrm{acc}}$ nominal units). Note; the purple plot is hypothetical as we are unable to allow physiological levels of $\mathrm{Ca}^{2+}$ enter the presynaptic terminal without neurotransmitter release being triggered and a subsequent postsynaptic contribution to the $\mathrm{pH}$ transient (if $7 \mathrm{mM}$ glutamate is not present in the saline).

Figure S4. The influence of synapse morphology on cleft pH. (A-B) Detail of the output plots of the computational model showing the impact of preventing access from the synaptic cleft to the void of the SSR. Detail unavailable in Figure 5. The dashed line represents the control conditions, i.e. bicarbonate buffering in the presence of medium CA activity, full access to the SSR and membrane permeability to $\mathrm{CO}_{2}$. Low, medium and high CA activity are 100, 600 and 2,000 $\mathrm{En}_{\mathrm{acc}}$ nominal units, respectively. $\mathrm{pH} 8.8$ represents the $\mathrm{pH}$ at which the PMCA is expected to stall [33]. (C-D) Detail of plots showing the impact of both preventing cleft access to the SSR, and preventing $\mathrm{CO}_{2}$ movement across membranes. 8,000 glutamate molecules released and $19 \mathrm{mM}$ bicarbonate buffering in all scenarios. Fusion pore opening $(\tau)$ is $1 \mu \mathrm{s} . \kappa$ indicates truncated acidic transients. 


\section{References}

1. Chesler, M., Regulation and modulation of $\mathrm{pH}$ in the brain. Physiol Rev, 2003. 83(4): p. 1183-221.

2. Obara, M., M. Szeliga, and J. Albrecht, Regulation of $\mathrm{pH}$ in the mammalian central nervous system under normal and pathological conditions: facts and hypotheses. Neurochem Int, 2008. 52(6): p. 905-19.

3. Sinning, A. and C.A. Hubner, Minireview: $p H$ and synaptic transmission. FEBS Lett, 2013. 587(13): p. 1923-8.

4. Wemmie, J.A., R.J. Taugher, and C.J. Kreple, Acid-sensing ion channels in pain and disease. Nat Rev Neurosci, 2013. 14(7): p. 461-71.

5. Zhao, $\mathrm{H}$., et al., Emerging roles of $\mathrm{Na}(+) / \mathrm{H}(+)$ exchangers in epilepsy and developmental brain disorders. Prog Neurobiol, 2016. 138-140: p. 19-35.

6. Zha, X.M., Acid-sensing ion channels: trafficking and synaptic function. Mol Brain, 2013. 6: p. 1.

7. Cho, S. and H. von Gersdorff, Proton-mediated block of Ca2+ channels during multivesicular release regulates short-term plasticity at an auditory hair cell synapse. J Neurosci, 2014. 34(48): p. 15877-87.

8. DeVries, S.H., Exocytosed protons feedback to suppress the Ca2+ current in mammalian cone photoreceptors. Neuron, 2001. 32(6): p. 1107-17.

9. Hirasawa, H., M. Yamada, and A. Kaneko, Acidification of the synaptic cleft of cone photoreceptor terminal controls the amount of transmitter release, thereby forming the receptive field surround in the vertebrate retina. J Physiol Sci, 2012. 62(5): p. 359-75.

10. Palmer, M.J., et al., Synaptic cleft acidification and modulation of short-term depression by exocytosed protons in retinal bipolar cells. J Neurosci, 2003. 23(36): p. 11332-41.

11. Vincent, P.F.Y., et al., Clustered $\mathrm{Ca}(2+)$ Channels Are Blocked by Synaptic Vesicle Proton Release at Mammalian Auditory Ribbon Synapses. Cell Rep, 2018. 25(12): p. 3451-3464 e3.

12. Beckwith-Cohen, B., et al., Localizing Proton-Mediated Inhibitory Feedback at the Retinal Horizontal Cell-Cone Synapse with Genetically-Encoded pH Probes. J Neurosci, 2019. 39(4): p. 651-662.

13. Wang, T.M., L.C. Holzhausen, and R.H. Kramer, Imaging an optogenetic $\mathrm{pH}$ sensor reveals that protons mediate lateral inhibition in the retina. Nat Neurosci, 2014. 17(2): p. 262-8.

14. Stawarski, M., et al., Neuronal Glutamatergic Synaptic Clefts Alkalinize Rather Than Acidify during Neurotransmission. Journal of Neuroscience, 2020. 40(8): p. 1611-1624.

15. Fedirko, N., et al., Regulation of postsynaptic Ca2+ influx in hippocampal CA1 pyramidal neurons via extracellular carbonic anhydrase. J Neurosci, 2007. 27(5): p. 1167-75.

16. Fedirko, N., N. Svichar, and M. Chesler, Fabrication and use of high-speed, concentric h+and Ca2+-selective microelectrodes suitable for in vitro extracellular recording. J Neurophysiol, 2006. 96(2): p. 919-24.

17. Gottfried, J.A. and M. Chesler, Temporal resolution of activity-dependent $\mathrm{pH}$ shifts in rat hippocampal slices. J Neurophysiol, 1996. 76(4): p. 2804-7. 
18. Makani, S., et al., NMDA receptor-dependent afterdepolarizations are curtailed by carbonic anhydrase 14: regulation of a short-term postsynaptic potentiation. J Neurosci, 2012. 32(47): p. 16754-62.

19. Makani, S. and M. Chesler, Endogenous alkaline transients boost postsynaptic NMDA receptor responses in hippocampal CA1 pyramidal neurons. J Neurosci, 2007. 27(28): p. 7438-46.

20. Makani, S. and M. Chesler, Rapid Rise of Extracellular pH Evoked by Neural Activity Is Generated by the Plasma Membrane Calcium ATPase. Journal of Neurophysiology, 2010. 103(2): p. 667-676.

21. Makani, S. and M. Chesler, Barium plateau potentials of CA1 pyramidal neurons elicit allor-none extracellular alkaline shifts via the plasma membrane calcium ATPase. J Neurophysiol, 2010. 104(3): p. 1438-44.

22. Tong, C.K., K. Chen, and M. Chesler, Kinetics of activity-evoked $\mathrm{pH}$ transients and extracellular pH buffering in rat hippocampal slices. J Neurophysiol, 2006. 95(6): p. 368697.

23. Du, J., et al., Protons are a neurotransmitter that regulates synaptic plasticity in the lateral amygdala. Proc Natl Acad Sci U S A, 2014. 111(24): p. 8961-6.

24. Gonzalez-Inchauspe, C., et al., Acid-Sensing Ion Channels Activated by Evoked Released Protons Modulate Synaptic Transmission at the Mouse Calyx of Held Synapse. J Neurosci, 2017. 37(10): p. 2589-2599.

25. Kreple, C.J., et al., Acid-sensing ion channels contribute to synaptic transmission and inhibit cocaine-evoked plasticity. Nat Neurosci, 2014. 17(8): p. 1083-91.

26. Li, H.S., et al., Protein Kinase C Lambda Mediates Acid-Sensing Ion Channel 1aDependent Cortical Synaptic Plasticity and Pain Hypersensitivity. J Neurosci, 2019. 39(29): p. 5773-5793.

27. Chen, H.Y. and M. Chesler, Autocrine boost of NMDAR current in hippocampal CA1 pyramidal neurons by a PMCA-dependent, perisynaptic, extracellular $\mathrm{pH}$ shift. J Neurosci, 2015. 35(3): p. 873-7.

28. Johansen, J., et al., Stereotypic morphology of glutamatergic synapses on identified muscle cells of Drosophila larvae. J Neurosci, 1989. 9(2): p. 710-25.

29. Stawarski, M., et al., The application of 'kisser' probes for resolving the distribution and microenvironment of membrane proteins in situ. J Neurogenet, 2018. 32(3): p. 236-245.

30. Heckmann, M. and J. Dudel, Evoked quantal currents at neuromuscular junctions of wild type Drosophila larvae. Neurosci Lett, 1998. 256(2): p. 77-80.

31. Somersalo, E., et al., A reaction-diffusion model of $\mathrm{CO} 2$ influx into an oocyte. J Theor Biol, 2012. 309: p. 185-203.

32. Desai, S.A. and G.A. Lnenicka, Characterization of postsynaptic Ca2+ signals at the Drosophila larval NMJ. J Neurophysiol, 2011. 106(2): p. 710-21.

33. Lnenicka, G.A., et al., Ca2+ dynamics along identified synaptic terminals in Drosophila larvae. J Neurosci, 2006. 26(47): p. 12283-93.

34. Atwood, H.L., C.K. Govind, and C.F. Wu, Differential ultrastructure of synaptic terminals on ventral longitudinal abdominal muscles in Drosophila larvae. J Neurobiol, 1993. 24(8): p. 1008-24.

35. Dickman, D.K., et al., Altered synaptic development and active zone spacing in endocytosis mutants. Curr Biol, 2006. 16(6): p. 591-8. 
36. Meinertzhagen, I.A., et al., Regulated spacing of synapses and presynaptic active zones at larval neuromuscular junctions in different genotypes of the flies Drosophila and Sarcophaga. J Comp Neurol, 1998. 393(4): p. 482-92.

37. Jia, X.X., M. Gorczyca, and V. Budnik, Ultrastructure of neuromuscular junctions in Drosophila: comparison of wild type and mutants with increased excitability. J Neurobiol, 1993. 24(8): p. 1025-44.

38. Zhan, H., et al., Three-dimensional imaging of Drosophila motor synapses reveals ultrastructural organizational patterns. J Neurogenet, 2016. 30(3-4): p. 237-246.

39. Fouquet, W., et al., Maturation of active zone assembly by Drosophila Bruchpilot. J Cell Biol, 2009. 186(1): p. 129-45.

40. Wong, K., S. Karunanithi, and H.L. Atwood, Quantal unit populations at the Drosophila larval neuromuscular junction. J Neurophysiol, 1999. 82(3): p. 1497-511.

41. Stiles, J.R., et al., Miniature endplate current rise times $<100 \mathrm{mu}$ s from improved dual recordings can be modeled with passive acetylcholine diffusion from a synaptic vesicle. Proceedings of the National Academy of Sciences of the United States of America, 1996. 93(12): p. 5747-5752.

42. Franks, K.M., T.M. Bartol, and T.J. Sejnowski, $A$ Monte Carlo model reveals independent signaling at central glutamatergic synapses. Biophysical Journal, 2002. 83(5): p. 23332348.

43. MacLean, D.M. and V. Jayaraman, Acid-sensing ion channels are tuned to follow highfrequency stimuli. J Physiol, 2016. 594(10): p. 2629-45.

44. MacLean, D.M. and V. Jayaraman, Deactivation kinetics of acid-sensing ion channel $1 a$ are strongly pH-sensitive. Proc Natl Acad Sci U S A, 2017. 114(12): p. E2504-E2513.

45. Lu, Z., et al., High-Probability Neurotransmitter Release Sites Represent an EnergyEfficient Design. Curr Biol, 2016. 26(19): p. 2562-2571.

46. Newman, Z.L., et al., Input-Specific Plasticity and Homeostasis at the Drosophila Larval Neuromuscular Junction. Neuron, 2017. 93(6): p. 1388-1404 e10.

47. Hernandez, R.X., et al., Comment on, Neuronal Glutamatergic Synaptic Clefts Alkalinize Rather Than Acidify during Neurotransmission. J Neurosci, 2020(12 September 2020).

48. Satzler, K., et al., Three-dimensional reconstruction of a calyx of Held and its postsynaptic principal neuron in the medial nucleus of the trapezoid body. J Neurosci, 2002. 22(24): p. 10567-79.

49. Green, A.A., The Preparation of Acetate and Phosphate Buffer Solutions of Known pH and lonic Strength. J. Am. Chem. Soc., 1933. 55(6): p. 2331-2336.

50. Bugg, N.C. and J.A. Jones, Hypophosphataemia. Pathophysiology, effects and management on the intensive care unit. Anaesthesia, 1998. 53(9): p. 895-902.

51. Goyal, R. and I. Jialal, Hyperphosphatemia, in StatPearls. 2021: Treasure Island (FL).

52. Guerrero, G., et al., Heterogeneity in synaptic transmission along a Drosophila larval motor axon. Nat Neurosci, 2005. 8(9): p. 1188-96.

53. Peled, E.S., Z.L. Newman, and E.Y. Isacoff, Evoked and spontaneous transmission favored by distinct sets of synapses. Curr Biol, 2014. 24(5): p. 484-93.

54. Borst, J.G. and B. Sakmann, Depletion of calcium in the synaptic cleft of a calyx-type synapse in the rat brainstem. J Physiol, 1999. 521 Pt 1: p. 123-33.

55. Brand, A.H. and N. Perrimon, Targeted gene expression as a means of altering cell fates and generating dominant phenotypes. Development, 1993. 118(2): p. 401-15. 
56. Macleod, G.T., Forward-filling of dextran-conjugated indicators for calcium imaging at the Drosophila larval neuromuscular junction. Cold Spring Harb Protoc, 2012. 2012(7): p. 791-6.

57. Macleod, G.T., et al., Fast calcium signals in Drosophila motor neuron terminals. J Neurophysiol, 2002. 88(5): p. 2659-63.

58. Olsen-Kettle, L., Numerical solution of partial differential equations. Lecture notes at University of Queensland, Australia, 2011.

59. Occhipinti, R., R. Musa-Aziz, and W.F. Boron, Evidence from mathematical modeling that carbonic anhydrase II and IV enhance CO2 fluxes across Xenopus oocyte plasma membranes. American Journal of Physiology-Cell Physiology, 2014. 307(9): p. C841C858.

60. Nicholson, C. and J.M. Phillips, Ion diffusion modified by tortuosity and volume fraction in the extracellular micro-environment of the rat cerebellum. Journal of PhysiologyLondon, 1981. 321(DEC): p. 225-257.

61. Nicholson, C. and E. Syková, Extracellular space structure revealed by diffusion analysis. Trends in neurosciences, 1998. 21(5): p. 207-215.

62. Savtchenko, L.P. and D.A. Rusakov, Glutamate escape from a tortuous synaptic cleft of the hippocampal mossy fibre synapse. Neurochemistry International, 2004. 45(4): p. 479-484.

63. Romero, M.F. and A.J. Rossano. Acid-Base Basics. in Seminars in nephrology. 2019. Elsevier.

64. Ruffin, V.A., et al., Intracellular $\mathrm{pH}$ regulation by acid-base transporters in mammalian neurons. Frontiers in Physiology, 2014. 5.

65. Harned, H.S., B.B. Owen, and C. King, The physical chemistry of electrolytic solutions. Journal of The Electrochemical Society, 1959. 106(1): p. 15C.

66. Roughton, F.J.W., The kinetics and rapid thermochemistry of carbonic acid. Journal of the American Chemical Society, 1941. 63: p. 2930-2934.

67. Occhipinti, R. and W.F. Boron, Role of Carbonic Anhydrases and Inhibitors in Acid-Base Physiology: Insights from Mathematical Modeling. International Journal of Molecular Sciences, 2019. 20(15).

68. Danbolt, N.C., Glutamate uptake. Progress in neurobiology, 2001. 65(1): p. 1-105.

69. Gordon, J.L., Extracellular ATP - effectes, sources and fate. Biochemical Journal, 1986. 233(2): p. 309-319.

70. Thomas, R.C., The plasma membrane calcium ATPase (PMCA) of neurones is electroneutral and exchanges $2 \mathrm{H}+$ for each $\mathrm{Ca} 2+$ or $\mathrm{Ba} 2+$ ion extruded. J Physiol, 2009. 587(2): p. 315-27.

71. Brini, M. and E. Carafoli, Calcium pumps in health and disease. Physiological reviews, 2009. 89(4): p. 1341-1378.

72. Franks, K.M., A Monte Carlo model of synaptic signaling. 2002, University of California, San Diego.

73. Sala, F. and A. Hernandez-Cruz, Calcium Diffusion Modeling in a Spherical Neuron Relevance of Buffering Properties. Biophysical Journal, 1990. 57(2): p. 313-324.

74. Scholl, J., et al., Precipitation of L-glutamic acid: Determination of nucleation kinetics. Chemical Engineering \& Technology, 2006. 29(2): p. 257-264. 
75. Cans, A.-S.U., et al., Counting the Number of Glutamate Molecules in Single Synaptic Vesicles. Biophysical Journal, 2020. 118(3): p. 454A-454A.

76. Atluri, P.P. and T.A. Ryan, The kinetics of synaptic vesicle reacidification at hippocampal nerve terminals. Journal of Neuroscience, 2006. 26(8): p. 2313-2320.

77. De Stefano, C., et al., Modeling ATP protonation and activity coefficients in NaClaq and KClaq by SIT and Pitzer equations. Biophysical Chemistry, 2006. 121(2): p. 121-130.

78. Edwards, R.H., The neurotransmitter cycle and quantal size. Neuron, 2007. 55(6): p. 835858.

79. Wheast, R.C., Handbook of chemistry and physics. 1983: CRC press.

80. Lide, D.R., CRC handbook of chemistry and physics. Vol. 85. 2004: CRC press.

81. Longsworth, L.G., DIFFUSION MEASUREMENTS, AT 25-DEGREES, OF AQUEOUS SOLUTIONS OF AMINO ACIDS, PEPTIDES AND SUGARS. Journal of the American Chemical Society, 1953. 75(22): p. 5705-5709.

82. Bowen, W.J. and H.L. Martin, Diffusion of adenosine triphosphate through aqueous solutions. Archives of Biochemistry and Biophysics, 1964. 107(1): p. 30-36.

83. Karunanithi, S., et al., Quantal size and variation determined by vesicle size in normal and mutant Drosophila glutamatergic synapses. J Neurosci, 2002. 22(23): p. 10267-76.

84. Carafoli, E., Calcium pump of the plasma membrane. Physiological reviews, 1991. 71(1): p. 129-153.

85. Llinas, R., M. Sugimori, and S.M. Simon, Transmission by presynaptic spike-like depolarization in the squid giant synapse. Proceedings of the National Academy of Sciences, 1982. 79(7): p. 2415-2419.

86. Penheiter, A.R., et al., A model for the activation of plasma membrane calcium pump isoform $4 b$ by calmodulin. Biochemistry, 2003. 42(41): p. 12115-12124.

87. Bartol, T.M., et al., Computational reconstitution of spine calcium transients from individual proteins. Frontiers in Synaptic Neuroscience, 2015. 7(17).

88. Yamoah, E.N., et al., Plasma membrane Ca2+-ATPase extrudes Ca2+ from hair cell stereocilia. Journal of Neuroscience, 1998. 18(2): p. 610-624.

89. Goldberg, J.H., et al., Calcium microdomains in aspiny dendrites. Neuron, 2003. 40(4): p. 807-821.

90. Koch, C., Biophysics of computation: information processing in single neurons. 2004: Oxford university press.

91. Markram, H., A. Roth, and F. Helmchen, Competitive calcium binding: Implications for dendritic calcium signaling. Journal of Computational Neuroscience, 1998. 5(3): p. 331348.

92. Schmidt, H., et al., Diffusional mobility of parvalbumin in spiny dendrites of cerebellar purkinje neurons quantified by fluorescence recovery after photobleaching. Biophysical Journal, 2003. 84(4): p. 2599-2608.

93. Crank, J., The mathematics of diffusion. 1979: Oxford university press. 


\section{APPENDIX}

To solve the diffusion equation numerically, we will discretize it in space to n concentric shells using a previous approach [31]. So $h=R / n, r_{j}=j h, 0 \leq j \leq n$,

We start with the equation

$$
\nabla \cdot\left(D_{i} \nabla c_{i}\right)=D_{i}\left(\frac{\partial^{2} c_{i}}{\partial r^{2}}+\frac{1}{r} \frac{\partial c_{i}}{\partial r}\right)
$$

where we have assumed $D_{i}$ is constant. Following [93], we can implement the finite difference approximation to discretize the diffusion equation as:

for $(1 \leq \mathrm{j} \leq \mathrm{n}-1)$

$$
\begin{aligned}
D_{i}\left(\frac{\partial^{2} c_{i}}{\partial r^{2}}+\frac{1}{r} \frac{\partial c_{i}}{\partial r}\right) & \approx D_{i}\left[\frac{c_{i, j+1}-2 c_{i, j}+c_{i, j-1}}{h^{2}}+\frac{1}{j h} \frac{c_{i, j+1}-c_{i, j-1}}{2 h}\right] \\
& =\frac{D_{i}}{h^{2}}\left[\left(1+\frac{1}{2 j}\right) c_{i, j+1}-2 c_{i, j}+\left(1-\frac{1}{2 j}\right) c_{i, j-1}\right]
\end{aligned}
$$

and for $(\mathrm{j}=0)$

$$
\mathrm{D}_{\mathrm{i}}\left(\frac{\partial^{2} \mathrm{c}_{\mathrm{i}}}{\partial \mathrm{r}^{2}}+\frac{1}{\mathrm{r}} \frac{\partial \mathrm{c}_{\mathrm{i}}}{\partial \mathrm{r}}\right) \approx \frac{\mathrm{D}_{\mathrm{i}}}{\mathrm{h}^{2}}\left(4 \mathrm{c}_{\mathrm{i}, 1}-4 \mathrm{c}_{\mathrm{i}, 0}\right)
$$

For simplicity let us define $\epsilon_{j}^{+}=D_{i}\left(1+\frac{1}{2 j}\right)$ and $\epsilon_{j}^{-}=D_{i}\left(1-\frac{1}{2 j}\right)$ where $1 \leq j \leq n-1$.

To apply the boundary conditions numerically, we used a method described previously [73], which is to introduce virtual shells. For the outermost shell, we consider both possibilities of boundary conditions as discussed in the Methods. For the Neuman boundary condition (the case where there is no flux), we assume the virtual external shell is in equilibrium with the outermost shell, i.e., $\frac{\partial c_{r}}{\partial r}(r=R, t)=0$, and, from there, we obtain $\frac{\partial c_{r}}{\partial r}(r=R, t) \approx \frac{c_{i, n+1}-c_{i, n}}{h}=0$ or $c_{i, n}=c_{i, n+1}$. So, for $(j=n)$ the Neuman boundary condition can be written as: 


$$
\mathrm{D}_{\mathrm{i}}\left(\frac{\partial^{2} \mathrm{c}_{\mathrm{i}}}{\partial \mathrm{r}^{2}}+\frac{1}{\mathrm{r}} \frac{\partial \mathrm{c}_{\mathrm{i}}}{\partial \mathrm{r}}\right) \approx \frac{\mathrm{D}_{\mathrm{i}}}{\mathrm{h}^{2}}\left(\epsilon_{\mathrm{n}}^{-} \mathrm{c}_{\mathrm{i}, \mathrm{n}-1}-\left(-2+\epsilon_{\mathrm{n}}^{+}\right) \mathrm{c}_{\mathrm{i}, \mathrm{n}}\right)
$$

For the Dirichlet boundary condition (constant concentration field), we assume that in the external virtual shell, the concentration of all the species is constant during the simulation, i.e., $c_{i, n+1}=\epsilon_{n}^{+} c_{i, \infty}$. As a result, for $(j=n)$ the Dirichlet boundary condition can be written as

$$
\mathrm{D}_{\mathrm{i}}\left(\frac{\partial^{2} \mathrm{c}_{\mathrm{i}}}{\partial \mathrm{r}^{2}}+\frac{1}{\mathrm{r}} \frac{\partial \mathrm{c}_{\mathrm{i}}}{\partial \mathrm{r}}\right) \approx \frac{\mathrm{D}_{\mathrm{i}}}{\mathrm{h}^{2}}\left(\epsilon_{\mathrm{n}}^{-} \mathrm{c}_{\mathrm{i}, \mathrm{n}-1}-(2) \mathrm{c}_{\mathrm{i}, \mathrm{n}}+\in_{\mathrm{n}}^{+} \mathrm{c}_{\mathrm{i}, \infty}\right) .
$$




\section{Figure 1}
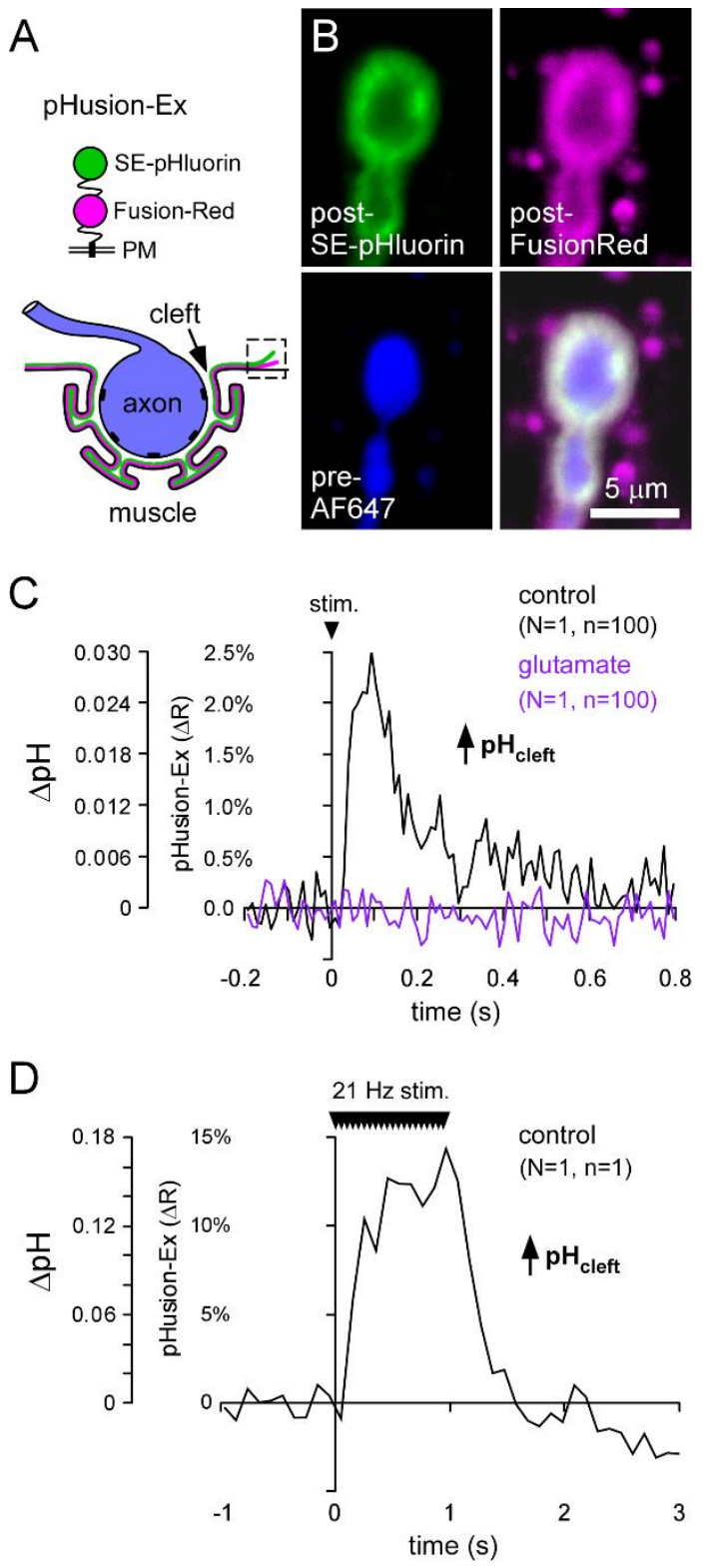

E time subsequent to a nerve impulse

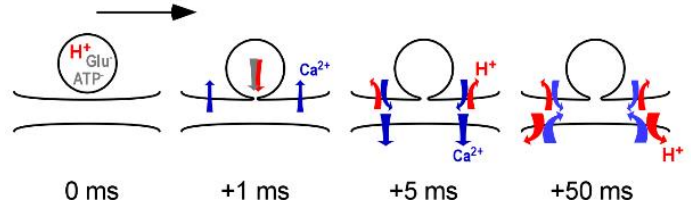




\section{Figure 2}

bioRxiv preprint doi: https://doi.org/10.1101/2021.06.30.450624; this version posted June 30, 2021. The copyright holder for this preprint (which was not certified by peer review) is the author/funder. All rights reserved. No reuse allowed without permission.

\section{Figure 3}

A


B EFFECTS OF BUFFERING

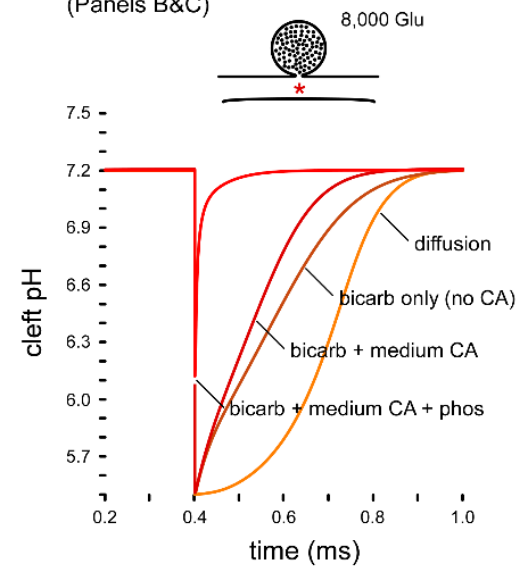

C



D EFFECTS OF SV LOADING

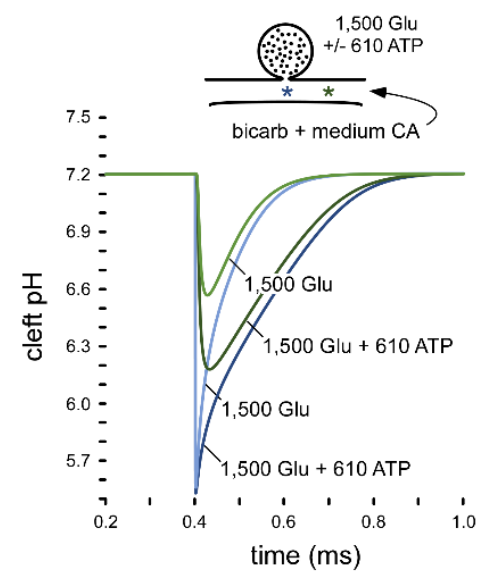

E EFFECTS OF EXOCYTOSIS KINETICS (Panels E\&F)

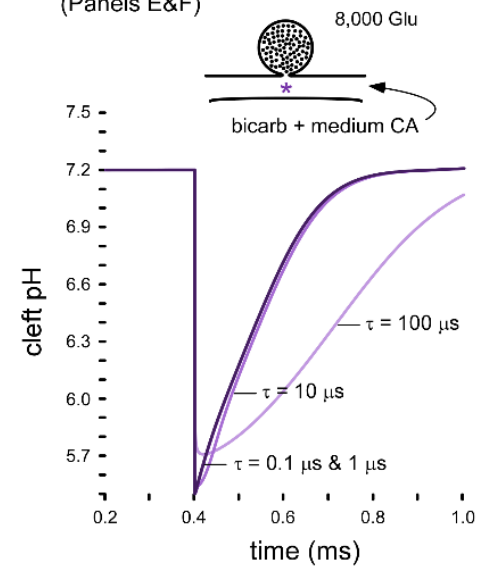

F

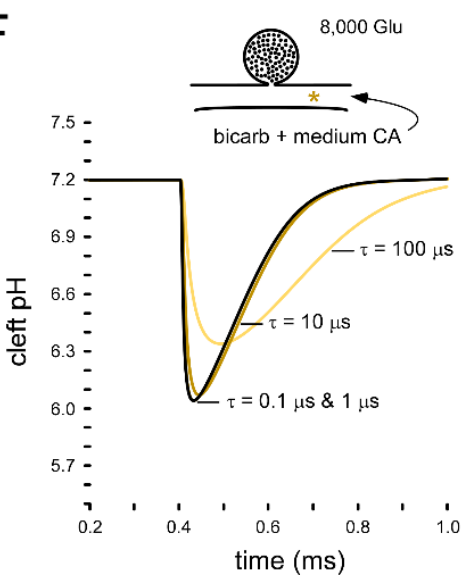


bioRxiv preprint doi: https://doi.org/10.1101/2021.06.30.450624; this version posted June 30, 2021. The copyright holder for this preprint (which was not certified by peer review) is the author/funder. All rights reserved. No reuse allowed without permission.

\section{Figure 4}

A



B

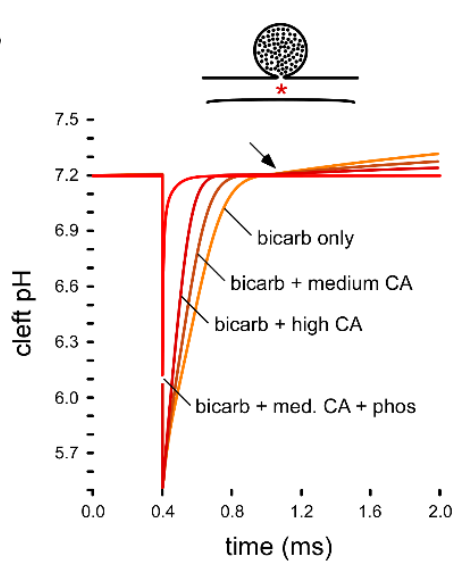

C

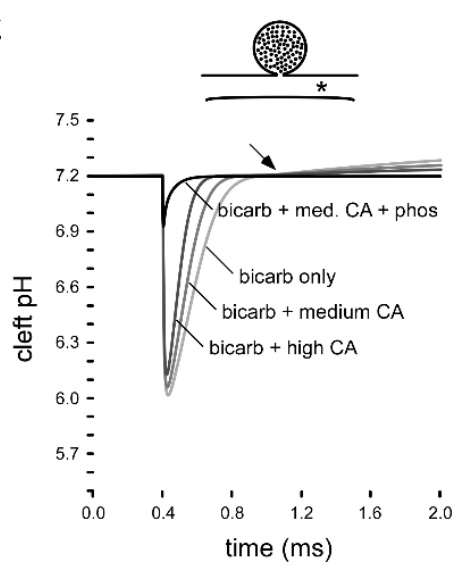

$\mathrm{D}$

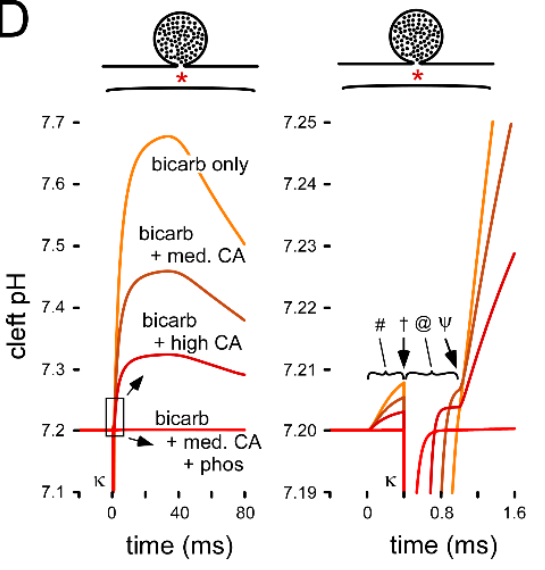

E

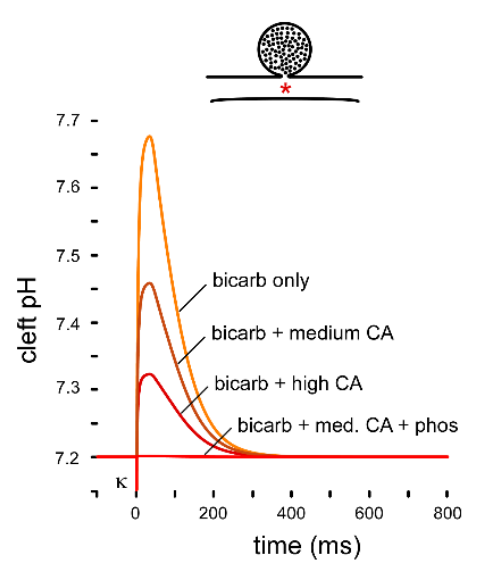

$\mathrm{F}$

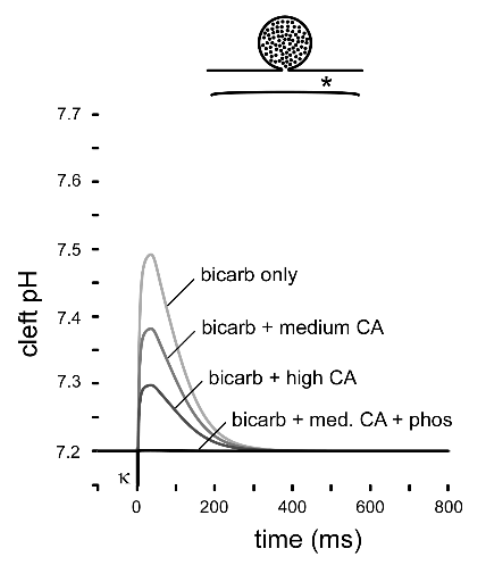


bioRxiv preprint doi: https://doi.org/10.1101/2021.06.30.450624; this version posted June 30, 2021. The copyright holder for this preprint (which was not certified by peer review) is the author/funder. All rights reserved. No reuse allowed without permission.

Figure 5 A CLOSED Cleft, BUt OPEN TO $\mathrm{CO}_{2}$
(Panels A\&B)



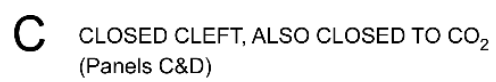
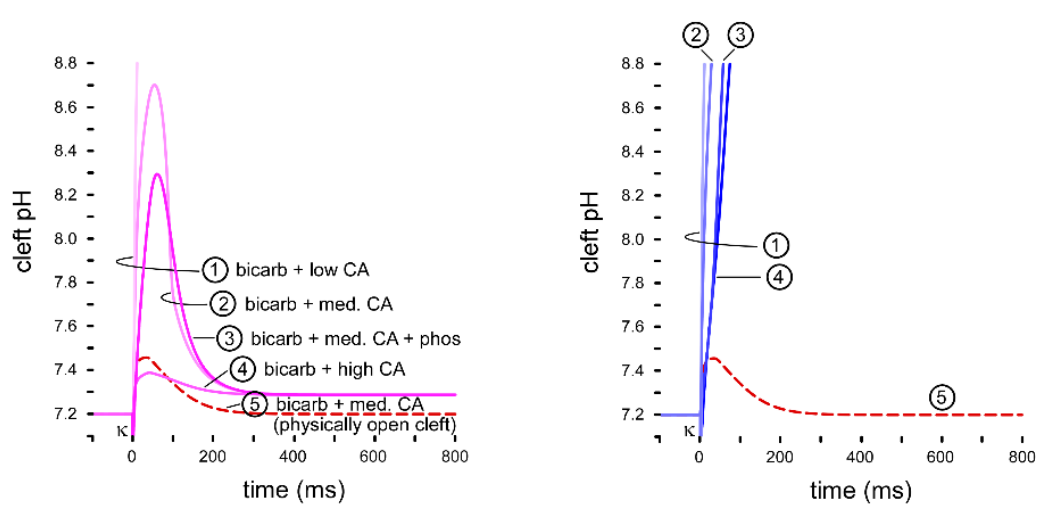

B

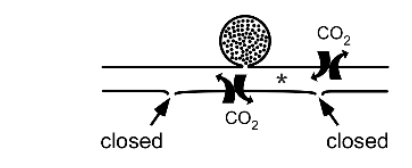

D
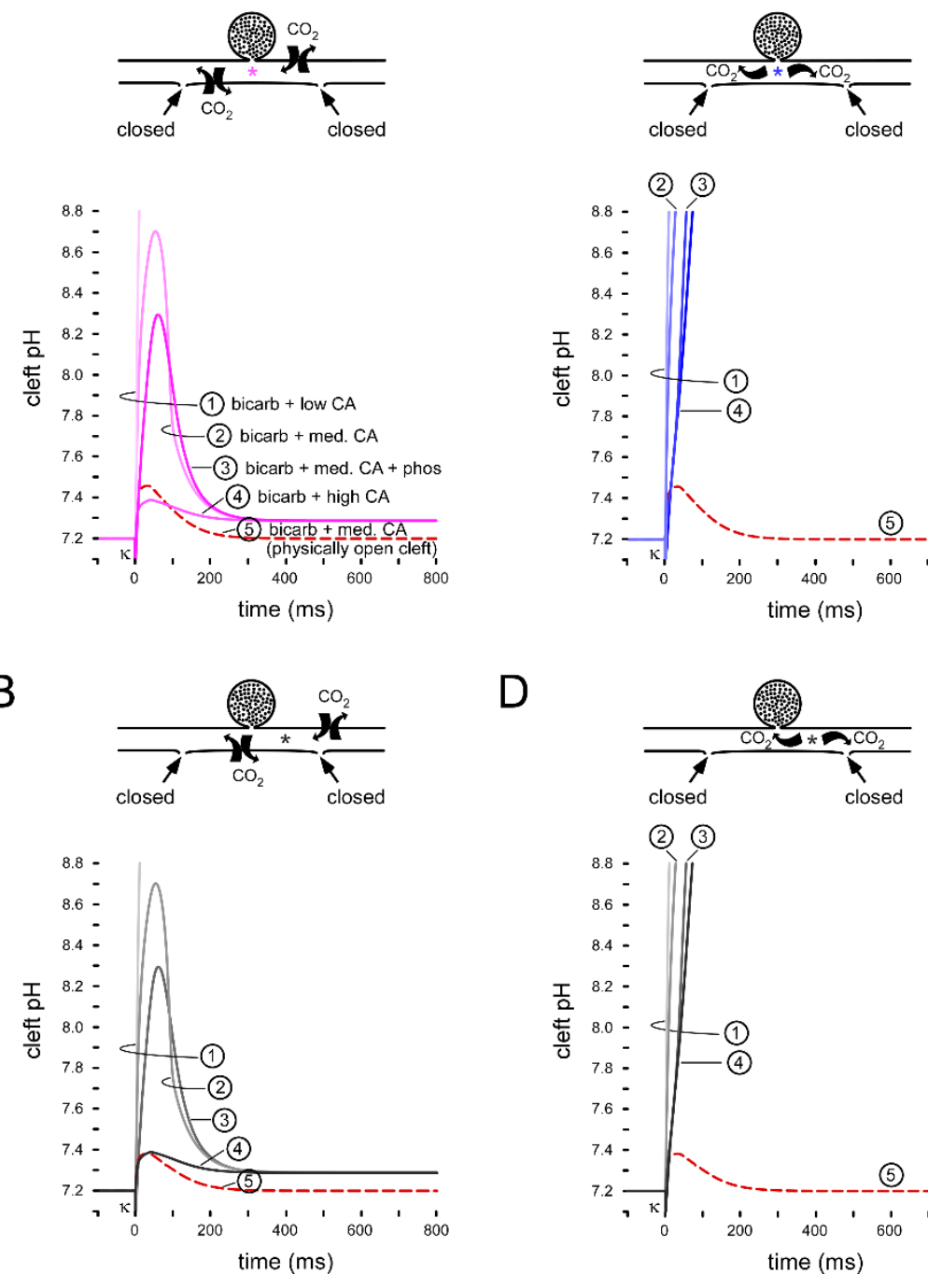


\section{Figure 6}

A<smiles>CC(C)C(C)F</smiles>

$\mathrm{Ca}^{2+}$ sensor $\quad \mathrm{pH}$ sensor

B
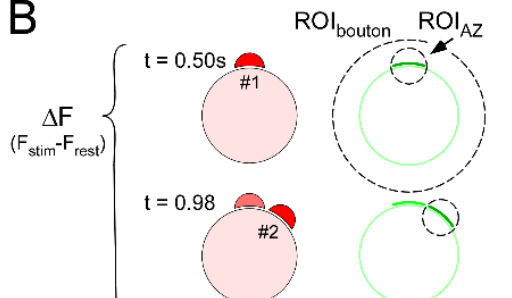

$\mathrm{t}=0.145 \Leftrightarrow$

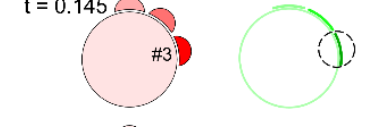

$t=0.193 \curvearrowleft$



$t=0.240$



$\mathrm{t}=0.288$

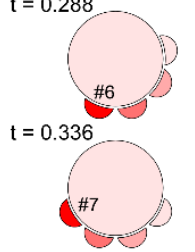

$\mathrm{t}=0.383$

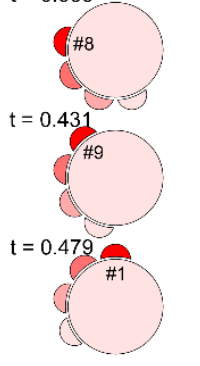

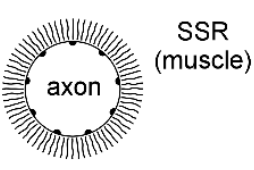

SSR

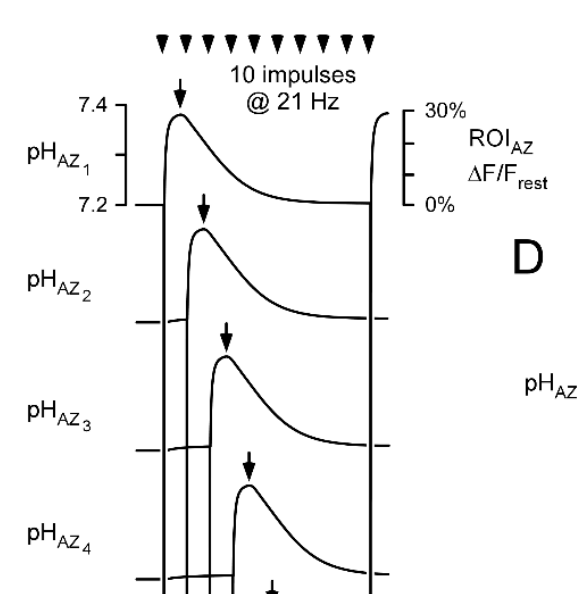

C
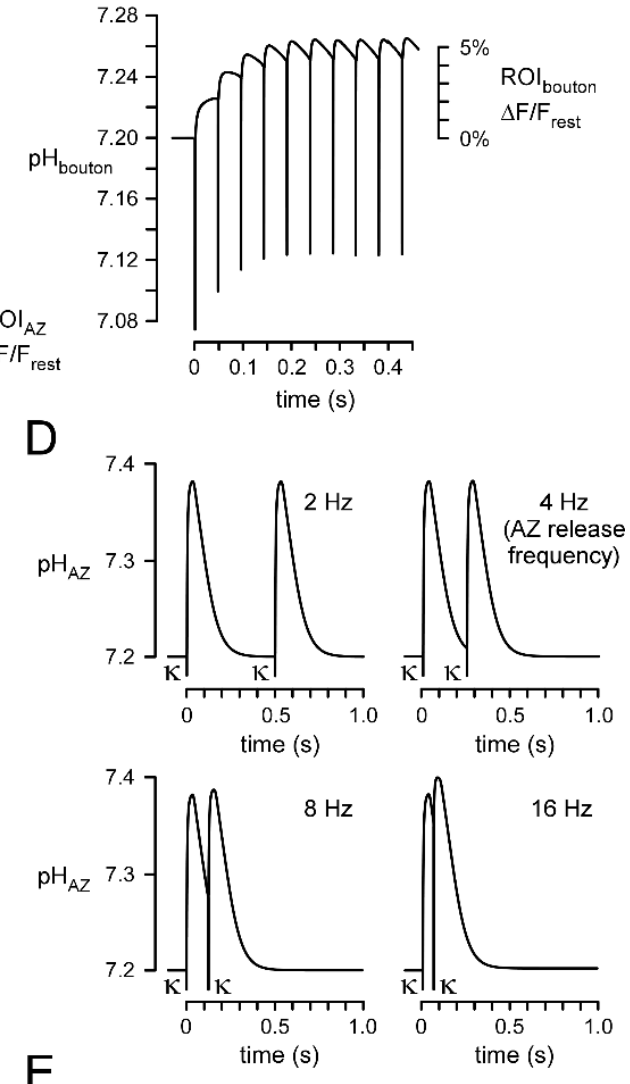

E

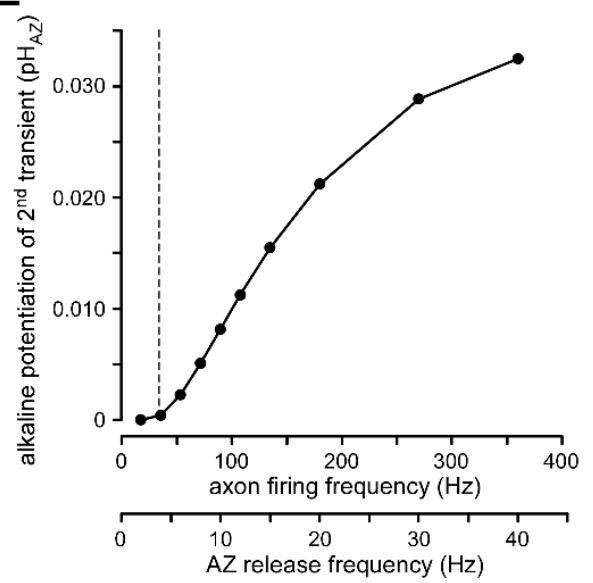


bioRxiv preprint doi: https://doi.org/10.1101/2021.06.30.450624; this version posted June 30, 2021. The copyright holder for this preprint (which was not certified by peer review) is the author/funder. All rights reserved. No reuse allowed without permission.

\section{Figure S1}

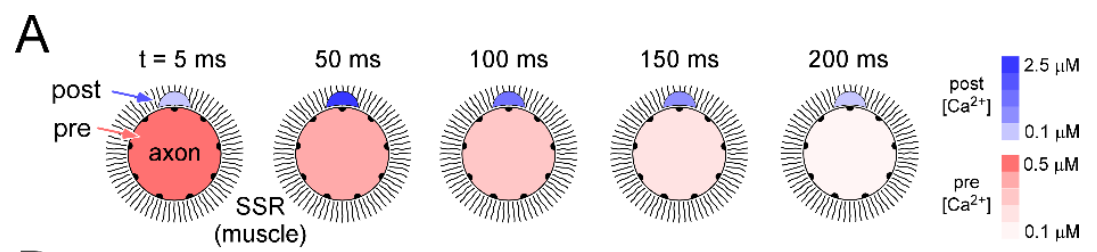

B

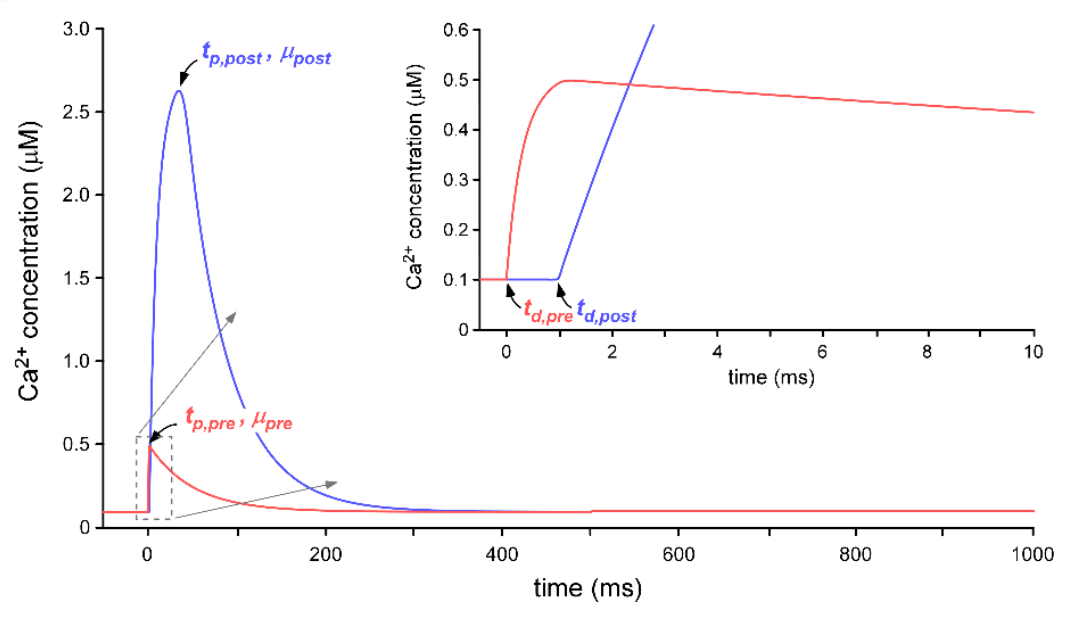


bioRxiv preprint doi: https://doi.org/10.1101/2021.06.30.450624; this version posted June 30, 2021. The copyright holder for this preprint (which was not certified by peer review) is the author/funder. All rights reserved. No reuse allowed without permission.

\section{Figure S2}

A Mole fraction of ionic species of glutamic acid versus $\mathrm{pH}$

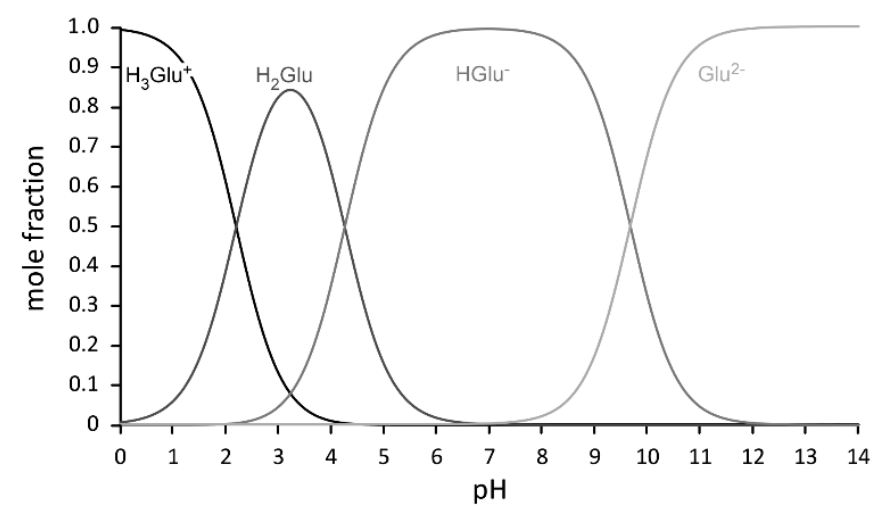

B Mole fraction of ionic species of ATP versus $\mathrm{pH}$




bioRxiv preprint doi: https://doi.org/10.1101/2021.06.30.450624; this version posted June 30, 2021. The copyright holder for this preprint (which was not certified by peer review) is the author/funder. All rights reserved. No reuse allowed without permission.

\section{Figure S3}

A
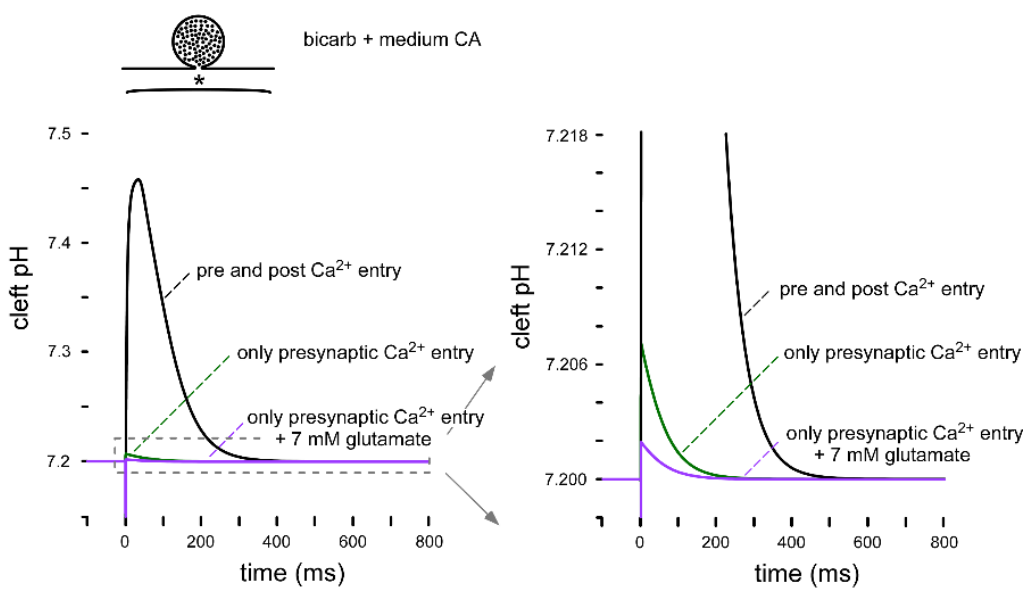

B
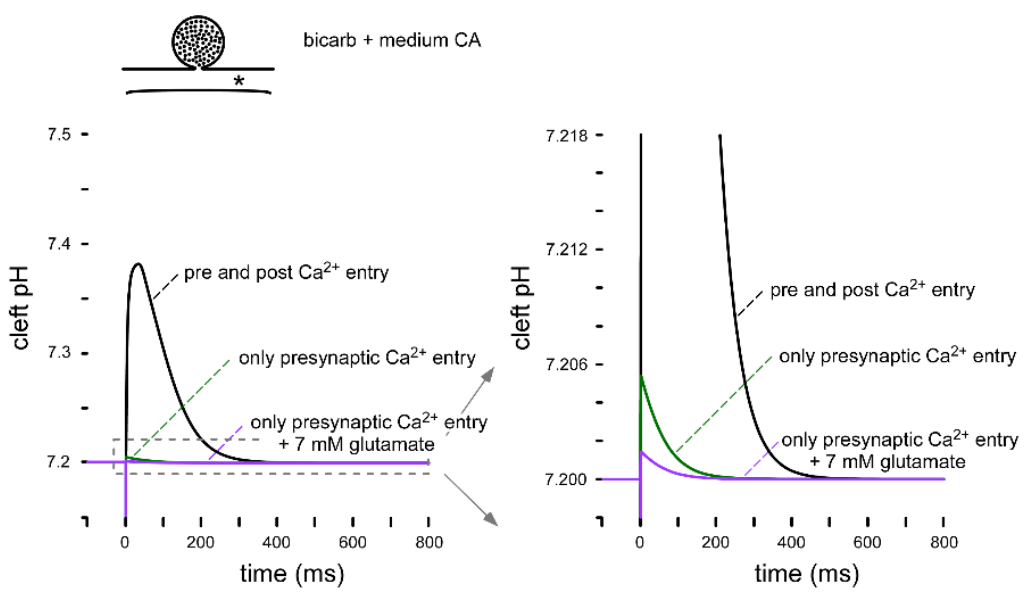

LEGEND FOR ALL PLOTS 


\section{Figure S4}

A CLOSED CLEFT, BUt OPEN TO $\mathrm{CO}_{2}$
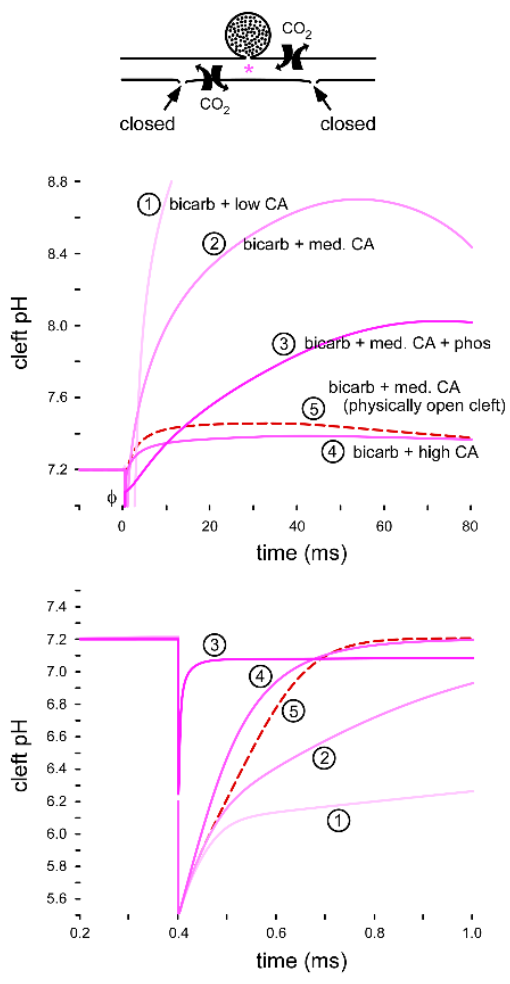

B
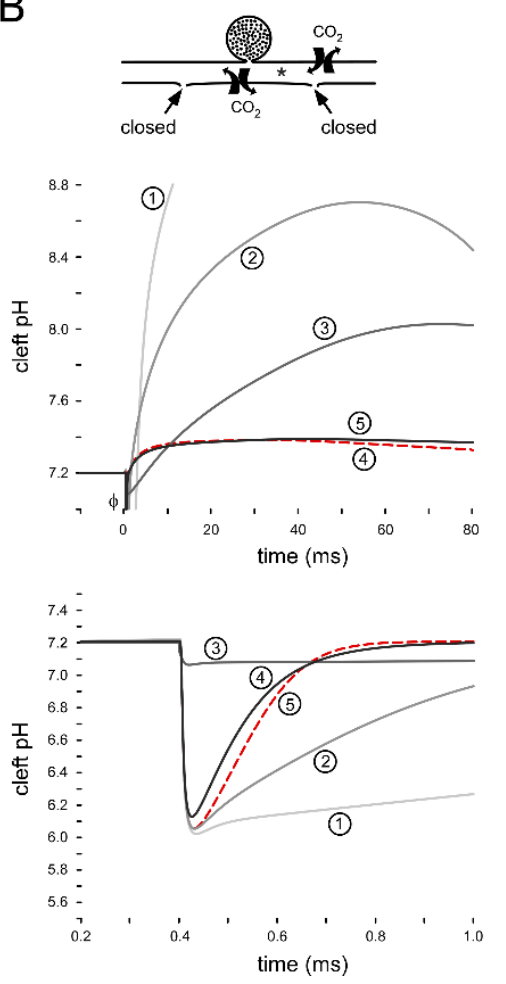

CLOSED CLEFT, Also CLOSED TO $\mathrm{CO}_{2}$
(C\&D)
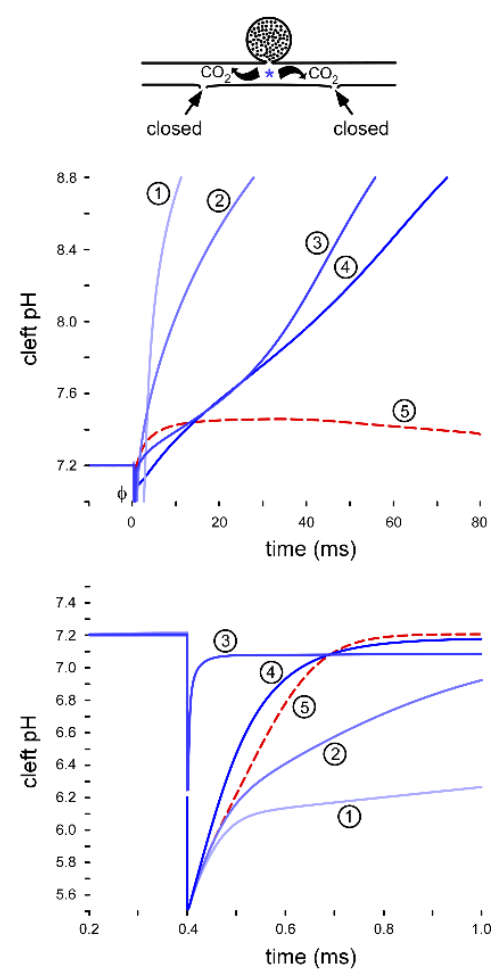

D
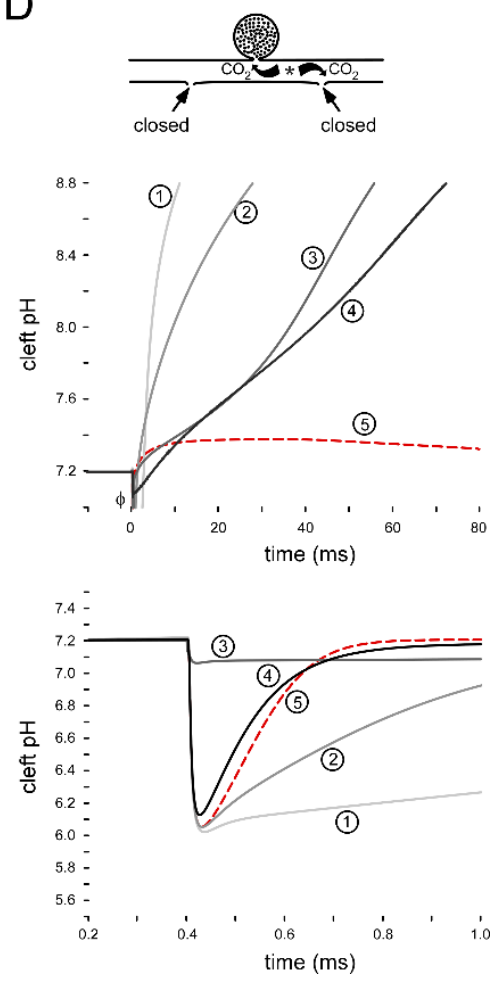